\title{
Labor Mobility and Technology Diffusion: a New Concept and its Application to Rural Southeast Asia
}

\author{
Michael Hübler ${ }^{\dagger}$ \\ Hannover Economic Papers (HEP) No. 554 \\ ISSN 0949-9962
}

February 2015

\begin{abstract}
We develop a new concept of rural technology diffusion influenced by labor mobility and business relations. The technology gain effect of labor mobility increases technology diffusiveness, whereas the technology drain effect decreases it. The concept is applied to survey data from the Mekong region, a new geographic area in this context. In the econometric analysis that takes spatial correlation and geographic variables into account, technology is measured in form of the number of mobile phones per village. The results support the technology gain and drain effects and show that labor mobility and business relations can help overcome geographic obstacles to rural development.
\end{abstract}

JEL Classifications: O18; O19; O33; O53

Keywords: technology diffusion; mobile phones; labor mobility; spatial correlation; rural development; Southeast Asia

\footnotetext{
${ }^{*}$ The responsibility for the contents of this discussion paper rests with the author. Since discussion papers are preliminary, it may be useful to contact the author about results or caveats.

${ }^{\dagger}$ Corresponding author, email: huebler@iuw.uni-hannover.de, tel: +49-511-762-19569, fax: +49-511762-2667, Leibniz Universität Hannover, Königsworther Platz 1, 30167 Hannover, Germany.
} 


\section{Introduction}

Advanced technologies, such as information and communication technologies (ICT), are often viewed as one promising way to overcome poverty traps. Therefore, it is important to better understand the drivers of technology diffusion within developing countries, especially in rural areas, and technology spillovers from abroad. Mobile phones play an extraordinary role in this context, because mobile communication systems can more easily and less costly be installed than fixed systems. This allows the fast spread of mobile communication systems and services in developing countries (cf. Minges, 1999; Banerjee and Ros, 2004; Hahn and Kibora, 2008) even in rural areas, where geographic remoteness and insufficient infrastructure create obstacles to technology diffusion and prevent the installation of fixed telecommunication systems. Mobile phones are accessible and affordable for villagers even in remote rural areas. They enable mobile communication and provide access to information, for example about prices on agricultural markets, new political developments or the situation of relatives and friends. Access to communication and information is an important step forward from a situation of poverty and lack of perspectives to overcome it. Since mobile phones are widely used in Africa, a recent literature stream has examined determinants of mobile phone use with focus on Africa (see section 2 and the summary by Buys et al., 2009). Following this literature stream, we examine geographic and socio-economic attributes and existing technologies as determinants of rural technology use in form of mobile phone use (ownership of or access to mobile phones).

Whereas the literature has extensively scrutinized trade and foreign direct investment (FDI) as vehicles for international technology diffusion (cf. the overviews by Saggi, 2002, and Keller, 2004), it has neglected migration. Particularly, the literature leaves open, what role socio-economic networks through national and international labor mobility, business activities and other economic relations play for international technology spillovers and technology diffusion in rural areas. We fill this gap by asking the question: are labor mobility and business relations relevant drivers of rural technology diffusion measured by mobile phone use? We hypothesize that the national and international mobility of workers and business relations, for example via small-scale enterprises or joint economic projects of villages, create socio-economic linkages that enhance the diffusion of technologies. We interpret technology diffusion in terms of the flow of technological knowledge, of physical technological devices as well as of the financial means that are necessary to acquire, use and maintain technological devices. In order to disentangle 
the channels of technology diffusion, we examine geographically differentiated measures (province, country, abroad as well as rural and urban) for labor mobility and business relations. Our survey data have the advantage of containing a rich set of economic and geographic indicators at the village-level that allow us to represent the economic and geographic integration of villages in detail.

The literature on technology diffusion and economic development has so far neglected Southeast Asia. Whereas former studies on the determinants and implications of mobile phone use focused on Africa, we fill this gap by focusing on the Southeast Asian Mekong region, which differs in terms of the political, economic and geographic conditions. More specifically, we study rural areas of the countries Thailand, Vietnam, Laos and Cambodia. Our study is one of the first that make use of the most recent survey data from these countries for 2013 (data for previous years have been introduced and applied by Hardeweg et al., 2012, 2013). Our data include for the first time Laos and Cambodia as new areas of research. The new data are consistent with the existing data for Thailand and Vietnam. For Laos and Cambodia, only the 2013 data wave is available. Therefore, we carry out a cross-section analysis for 2013 that includes villages in Thailand, Vietnam, Cambodia and Laos. Technology diffusion across villages is modeled in form of spatial correlation of mobile phone use between neighbor villages. Although mobile phones are very wide-spread in these countries, in 2013 mobile phone coverage still varied significantly across villages so that research into its determinants appears promising.

We proceed as follows. Section 2 positions our work in the literature. Section 3 develops a new conceptual model of rural technology diffusion with focus on labor mobility and business relations. Based on that, section 4 describes the data and carries out and discusses the econometric analysis. Section 5 concludes.

\section{Relation to the literature on technology diffusion}

Our work is embedded in the following macro- and micro-economic literature streams.

At the macro-economic level, an extensive literature has examined international technology spillovers driven by international trade and foreign direct investment and found mixed results (cf. the overviews by Saggi, 2002, and Keller, 2004; more specifically e.g. Mazumdar, 2001, Hübler and Keller, 2010, for energy intensities of developing countries, Kretschmer et al., 2011, for foreign aid; Du, Harrison and Jefferson, 2012, Xu and Sheng, 2012, and $\mathrm{He}$ and $\mathrm{Mu}, 2012$, for FDI in China). Another broad macro-economic liter- 
ature has on the one hand identified the benefits generated by international migration of educated workers, especially via diaspora networks. It has on the other hand identified the drawbacks of international migration, especially the so-called brain drain (cf. the overviews by Commander et al., 2004, and Kuznetsov, 2006). Our work transfers this macroeconomic view of migration to the micro-level. Though, not all countries can benefit from technology spillovers to the same extent. A prominent literature stream has identified a global digital divide with respect to information and communication technologies (e.g. Chinn and Fairlie, 2007). In this context, it has been shown that better education and policies that promote competition and economic growth foster the spread of mobile phones across developing countries and help overcome the digital divide, whereas higher (per capita) income is not necessarily a main driver of technology diffusion (Kiiski and Pohjola, 2002; Dasgupta et al., 2005). Though, independent moderate regulation of the telecommunication market is preferable over strict or no regulation (Howard and Mazaheri, 2009). Other results confirm income and policy (in this case trade policy) as relevant determinants for the diffusion of information and telecommunication technologies (ICT), but question education and political freedom (Baliamoune-Lutz, 2003). In the following micro data-based study, we will test the impact of wealth and access to schooling on technology diffusion.

For the micro-economic level, econometric and model-based approaches have been developed that describe the diffusion of technologies in developing countries, in particular the adoption of agricultural innovations (cf. the critical reviews by Besley and Case, 1993, and Doss, 2006; cf. Berger, 2001, for an agent-based spatial model). In the following analysis, we model rural technology diffusion following the spatial-econometric view on diffusion processes with the help of spatial correlations of neighbor entities (cf. LeSage, 1999; for a critical discussion of economics and spatial econometrics see Corrado and Fingleton, 2012). With respect to modern information and communication technologies, a recent literature stream has identified determinants of mobile phone use with focus on Africa (cf. the summary by Buys et al., 2009, referring to BaliamouneLutz, 2003, Kamssu, 2005, and others). Accordingly, geographic factors, income, socioeconomic characteristics and existing ICT are viewed as relevant determinants. We will therefore include these determinants in our micro data analysis. In the literature particularly insufficient competition and geographic remoteness are identified as obstacles to technology diffusion that can generate a digital divide (Buys et al., 2009). The recent literature has also scrutinized the impacts of mobile phone use and found, for example, that mobile phones can ease the access to markets for agricultural products in Africa 
(e.g. Muto and Yamano, 2009; cf. the overview by Heeks, 2010). Jensen (2007) uses micro-level survey data from Kerala, India, and shows that mobile phone use by fishermen and wholesalers drastically reduce price dispersion in the local market for fish. We will not look at the impacts of mobile phone use in this analysis, though, but concentrate on its determinants. Anecdotic evidence from developing countries describes that mobile phones are used for communication with migrant kinsmen (Paragas, 2010). There is also anecdotic evidence that migrant workers not only bring remittances to their relatives residing in rural areas, but also mobile devices (Hahn and Kibora, 2008). This motivates our research focus on the relation of migrant workers and technology diffusion. We improve on this literature by providing econometric results. The connection of migrant workers and technology diffusion is related to the literature on social networks. On the one hand, this literature highlights the impact of social networks and peer groups on product choice (cf. Richards et al., 2014), whereby a product would be a mobile phone in our context. On the other hand, this literature demonstrates that mobile phones are used for creating and maintaining social networks (cf. Horst and Miller, 2005, on mobile phone use by low-income Jamaicans). Research on ICT diffusion in Latin America, however, cautions against a too optimistic view of the ICT potential for economic development: policy support would need to drastically subsidize ICT (i.e. reduce prices for ICT) in order make ICT affordable for the myriads of people in severe poverty (Hilbert, 2010). Notably, the econometric literature seems to leave open, what role business relations, for example via small-scale enterprises, play in technology diffusion in developing countries. Against this backdrop, we are searching for economic linkages that support the diffusion of technologies among the poor, in particular, labor mobility and business relations.

\section{A conceptual model of rural technology diffusion}

This section sheds light on the micro-level determinants of technology diffusion in rural areas in developing countries. The first subsection develops a conceptual framework that describes rural technology diffusion. The second subsection describes labor mobility as the driver of technology diffusion in the spotlight in mathematical form and formulates testable hypotheses. Based on that, the third subsection sets up an econometric model. 


\subsection{Conceptual framework}

Before dealing with the determinants of technology diffusion, we need to define what technology diffusion means in our context. According to our definition, the term 'technology' encompasses technological knowledge, for example about the existence and the use of a mobile phone, as well as physical devices, for example a mobile phone itself. The flow of technological knowledge is abstract and not directly observable. Hence, it is measured via its physical or economic impact, for example the use of a mobile phone by a villager. The physical diffusion of technologies can either occur in form of physical devices themselves, e.g. trade in mobile phones, or in form of financial transfers that are used to buy physical devices. We can only observe the physical or economic result, i.e. the access to, and expectedly the use of mobile phones, without disentangling these effects.

Regarding the determinants of technology diffusion, we focus on labor mobility as a driver of the spread of technologies in rural areas in developing countries. We define labor mobility in a broader sense so that it encompasses commuters as well as emigrants and immigrants. We also take into account business relations, i.e. business activities and economic (development) projects that are both related to personal contacts and the mobility of people across the borders of geographic entities. Additionally, we take into account geography, such as the remoteness of a village measured in various ways like travel time to the next town, distance to the next school or connections to neighbor villages, society, such as the age and income structure of a village, and technology with respect to existing complementary technologies such as access to electricity or the internet. Figure 1 illustrates these determinants.

The centre of the figure shows one geographic entity $n$ of in total $N$ entities, for instance villages. It is the aim of our research to measure technology use within each entity and its interdependency with technology use in other entities and other geographic areas. This interdependency implies technology diffusion processes. The structure of society and complementary technologies are the two determinants of technology use that are defined within the boundaries of an entity. We expect that social factors influence technology use (cf. Buys et al., 2009, referring to Baliamoune-Lutz, 2003, Kamssu, 2005, and others). In our context, younger people might use technologies more often than older people, richer people more often than poorer people, or larger households might use more devices than smaller households. Referring to the concepts 'absorptive capacity' (e.g. Girma, 2005) and 'distance to technology frontier' (going back to Nelson and Phelps, 


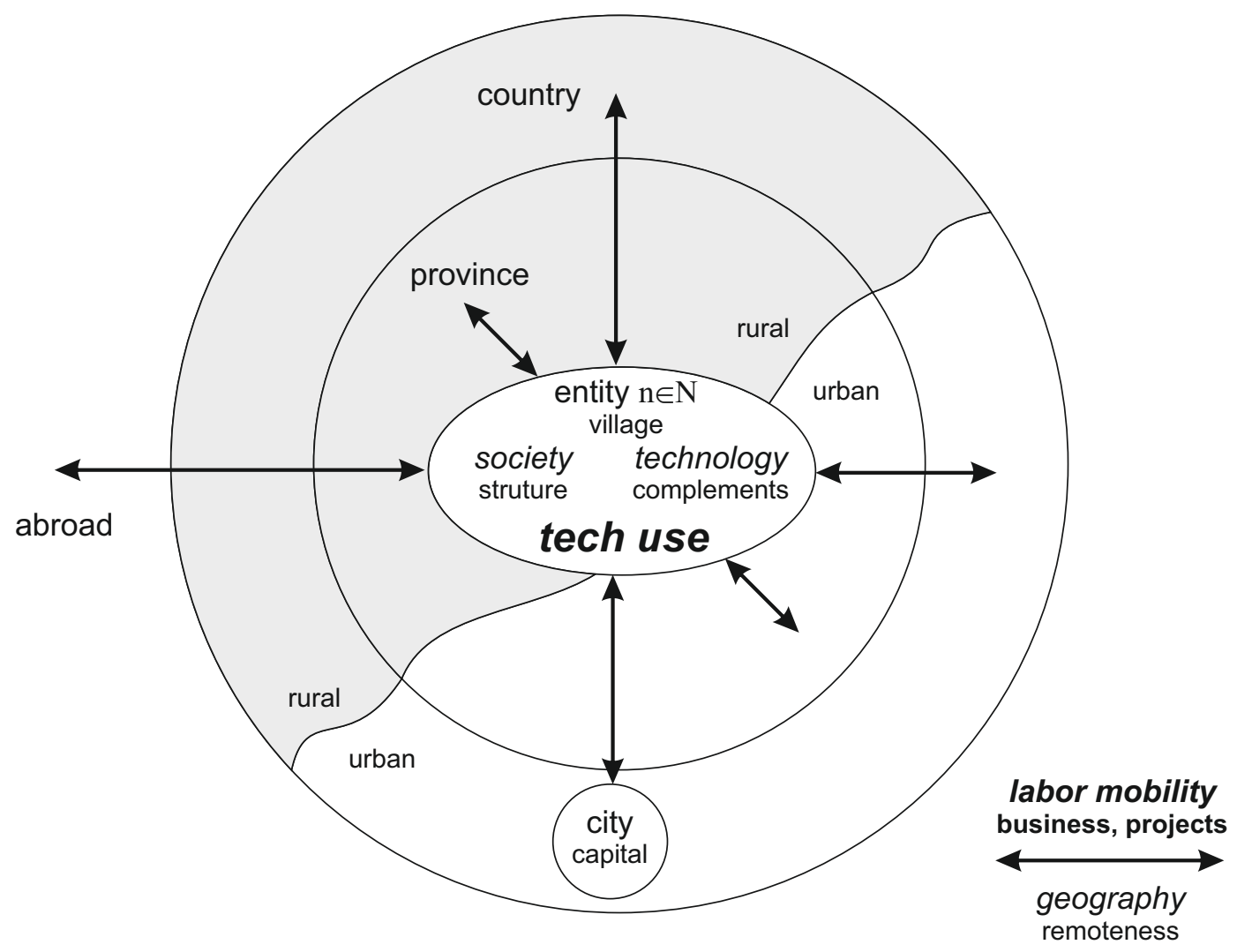

Figure 1: Determinants of technology diffusion in a rural area that results in technology use in an entity $n$ like a village. Geographic linkages and particularly linkages via labor mobility, business relations and joint projects are defined between the entity and its surroundings, indicated by the six double-arrows. The surroundings encompass various levels: province, country, (capital) city and abroad. Each level is split into a rural part (colored grey) and an urban part (colored white). 
1966), existing technologies can be complements to or prerequisites for the newly adopted technologies under scrutiny. In this sense, existing technologies can ease and support the adoption of new technologies by building on the existing technological knowledge and capability. Or they can slow down the adoption of additional new technologies that are substitutes for the existing technologies and hence partly superfluous (cf. Dechezleprêtre et al., 2013). Notably, we do not distinguish between mobile phones and cell towers as a prerequisite for mobile communication in our analysis. (The data, which we will describe later, indicate that almost all villages are at least partly equipped with cell towers.)

The two determinants geographic remoteness and labor mobility are defined between an entity and its surroundings, indicated by the six double-arrows. The arrows connect an entity with different levels and types of the surrounding. First, there can be connections to other entities within the same province, outside the province, but within the same country, and outside the country. This distinction is important with respect to technology diffusion, because one expects a higher occurrence of modern technologies in emerging or industrialized economies abroad, where people tend to migrate to, than within the developing economy under examination. Hence, connections to these hightechnology countries are important for technology diffusion. Furthermore, there might be areas like provinces with different technology levels within the same developing country so that technology diffusion across provinces is of particular interest. Second, there can be connections to entities in rural areas or to entities in urban areas, especially to towns within the developing country. The capital city of the country is highlighted as one specific, important urban entity in the figure. The distinction between rural and urban areas is relevant, because one expects a higher occurrence of modern technologies in urban than in rural areas. In general, we expect that the magnitude of technology diffusion declines with a larger distance between the entities involved in technology diffusion (villages to village or village to city; cf. Buys et al., 2009, and their summary of the literature) and with lower accessibility of an entity via roads or water. This expectation follows the gravity model of international trade and the fact that diffusion processes decay in space with larger distances, which is taken into account by spatial econometric approaches (cf. LeSage, 1999). Additionally, there can be province- or country-specific determinants of technology use that are not explicitly known and specified. As a result, we obtain a concept of technology diffusion that views each geographic entity, such as a village in a developing country, as being embedded into different larger geographic units and being more or less connected to these larger units.

From an economic point of view, prices for the acquisition and use of technologies 
are another relevant driver. They are not the focus of the following analysis, though. In our analysis, we assume that these prices are approximately constant across villages, at least within one country or province. Technology-related prices will presumably fall over time, yet, we do not consider dynamic behavior in our analysis. Furthermore, the use of technical devices may require the existence of specific technical and economic infrastructure. For example, the use of mobile phones (cellular phones) requires the existence of cell towers and of telecommunication service providers in the area of mobile phone use. Our conceptual framework abstracts from such infrastructural prerequisites and studies the use of a technological devices such as a mobile phone itself. The use of mobile phones in a village, however, necessarily implies the existence of cell towers and telecommunication services. We capture the possibility to install communication infrastructure implicitly via geographic accessibility and distance measures. Based on empirical findings, we presume that almost all entities have (at least partial access) to telecommunication nets and services.

\subsection{Labor mobility}

The spotlight of this study is on labor mobility in a broader sense, including business relations. Labor mobility can, for example, occur from rural to urban areas, fostered by higher wages and hindered by unemployment in the urban region (e.g. described in the classical theory by Harris and Todaro, 1970). The following analysis focuses on the impacts of labor mobility, rather than on its drivers. Although the impact of labor mobility on technology use is not trivial, a clear-cut concept is missing in the literature. In our view, labor mobility and migration create and strengthen socioeconomic networks, which in turn enhance technology diffusion. This view relates to the literature on social networks and peer groups (e.g. Horst and Miller, 2005; Richards et al., 2014). Our concept, however, leaves open whether rural technology diffusion is driven by knowledge flows, by physical flows of technical devices or by financial flows (remittances) that in turn enable the acquisition of technical devices. We expect that these three aspects jointly enhance technology diffusion.

This section details the impact of labor mobility on technology use from a general conceptual perspective. Let us first consider the situation of people who live in an entity $n$, say a village, and create connections to the surroundings that enhance technology diffusion. The people can be permanent residents of the entity who work outside the entity and commute. They can be residents involved in business activities as well. They might, for example, sell agricultural products on nearby markets and use mobile phones 
to communicate with business partners outside the entity. Moreover, they can be government employees who live in the entity and exchange information via the administrative system. They can also be external persons who did not grow up within the entity or foreigners who now live within the entity and have become permanent residents. We expect that the presence of these persons, who all belong permanently to the population of the entity, enhances technology diffusion due their outside connections and business relations and hence increases technology use in the entity. In addition, with respect to telecommunication, it is more useful to own mobile phones, if one spends more time outside the village in order to communicate with relatives and friends inside the village. Let us summarize these aspects more formally:

$$
\begin{aligned}
& T^{n}=\theta P^{n}+\theta^{C} C^{n}, \quad P^{n}=P^{n 0}+C^{n} \\
\Leftrightarrow & T^{n}=\theta\left(P^{n 0}+C^{n}\right)+\theta^{C} C^{n} \\
\Leftrightarrow & T^{n}=\theta P^{n 0}+\left(\theta+\theta^{C}\right) C^{n}
\end{aligned}
$$

$n$ denotes one of $N$ entities as before. $T^{n}$ is a measure for technology use and signifies the number of technical devices in entity $n . P^{n}$ is the total population of entity $n$. It consists of the base population, denoted by $P^{n 0}$, and the special groups of permanent residents, $C^{n}$, discussed above, commuters, business people and residents born outside the entity. $\theta$ describes the number of technical devices per resident of the base population. These special groups are supposed to use more technical devices and bring about more information about new technologies than the base population. We can hence interpret $\theta^{C}$ as a technology markup that characterizes the additional technology use on top of $\theta$ associated with these groups. We can formulate the following testable hypothesis which we call technology gain hypothesis:

Hypothesis 1. Specific groups $C^{n}$ of the permanent population of an entity $n$, such as commuters, business people or residents born outside the entity, enhance technology diffusion and technology use in $n$ and hence create a technology markup $\theta^{C}>0$ over the average per capita technology use $\theta$ in $n$.

The relation becomes somewhat more complicated in case of emigrants, $E^{n}$, who leave the entity and are no longer permanent residents of it.

$$
T^{n}=\theta P^{n}+\theta^{E} E^{n}, \quad P^{n}=P^{n 0}
$$

Now there are two opposing effects. On the one hand, emigrants have relatives, friends 
and possibly business partners in their former residence. This creates a link that enhances technology diffusion and increases the demand for mobile communication between relatives, friends and business partners like in the case of permanent residents. The emigrants may provide information about new technologies to the permanent residents, send remittances or technical devices. With respect to telecommunication, the wish to communicate with emigrated relatives and friends may increase the use of mobile phones in the entity. This resembles the technology gain hypothesis.

There is, however, an additional aspect: the person who generates the technology spillover is not residing within the entity, but at a certain distance to it. Referring to the gravity model, one can expect that the strength of the link weakens the farther the emigrant is away from the home entity. Referring to diffusion processes, we also expect that the strength of the process decreases in the distance between the source of the impact and the realization of the impact. On the contrary, one might argue that the usefulness an necessity of telecommunication increases in the distance between the new residence of migrants and their origin $n$. This is, however, not necessarily true, because mobile communication with relatives or friends is desirable independent of the distance to them. In this sense, the role of the migration distance is ambiguous. Nonetheless, the usefulness of telecommunication devices is higher when workers have migrated than when they are commuters who can see their family and friends every day. As mentioned in the previous section, we expect a higher occurrence of modern technologies in urban than in rural areas. As a result, the technology spillover is expected to be stronger for connections with urban than with rural areas. The technology gain hypothesis now reads:

Hypothesis 2. (a) Emigrants, in particular emigrant workers, $E^{n}$, who left an entity $n$, are still connected with $n$ and enhance technology diffusion and technology use in $n$; hence they create a technology markup $\theta^{E}>0$ over the average per capita technology use $\theta$ in $n$. (b) This relationship and hence the markup decline in the distance between $n$ and the new place of residence. (c) This relationship and hence the markup are higher if the new place of residence is urban than when it is rural.

If we consider migration to abroad, the positive effect will be higher for destinations with a higher technology level (industrialized countries) and lower for destinations with a low technology level (developing countries). The intuition is that one cannot learn as much from foreign countries that are similar or worse in terms of knowledge and technologies than from countries that are superior. 
On the other hand, emigrants likely have linkages to outside the entity already before they emigrate. Hence, they are better informed and might have a stronger affinity to technologies than residents whose scope of interest is restricted to the entity. Before emigrating, they are part of the entity's population and presumably raise technology use like the special groups discussed above. Therefore, on the other hand, this enhanced technology use vanishes once the emigrants leave the entity. Consequently, the number of technical devices per resident is ex ante emigration higher than ex post. Referring to the brain drain debate, let us formulate the following technology drain hypothesis:

Hypothesis 3. When emigrants, in particular emigrant workers, $E^{n}$, who have an above-average technology affinity, leave an entity $n$, the average number of technical devices per capita declines so that a negative technology markup $\theta^{E}<0$ occurs.

If $\theta^{E}=0$, migrants have the same technology affinity as the remaining residents, and migration leaves per capita technology use $T^{n} / P^{n}$ unaffected. If $\theta^{E}<0$, migrants have a higher technology affinity than the remaining residents, and migration reduces per capita technology use $T^{n} / P^{n}$. This argumentation, however, hinges upon the assumption that emigrants have an above-average affinity to technologies.

Hypotheses 2 and 3 together imply that overall for $\theta^{E}>0$ the technology gain effect dominates, whereas for $\theta^{E}<0$ the technology drain effect dominates.

\subsection{Econometric model}

We transfer the considerations of the previous sections into the following linear econometric model:

$$
T^{n}=\beta^{1} P^{n}+\vec{\beta}^{2} \vec{C}^{n}+\vec{\beta}^{3} \vec{E}^{n}+\vec{\beta}^{4} \vec{S}^{n}+\vec{\beta}^{5} \vec{G}^{n}+\beta^{6} \vec{W}^{n} \vec{T}^{n}+\vec{\beta}^{7} \vec{D}^{n}+\vec{\beta}^{0}+\epsilon^{n}
$$

$n$ denotes an entity $n$, in particular a village, as before. The coefficients to be estimated are represented by $\beta$. In the following, we will use to the number of households in $n$ as a (unit) measure for most population-related variables. $T$ measures the number of households in $n$ that utilize, i.e. own or have access to a technical device, in particular at least one mobile phone. $P$ measures the total number of households in $n . \beta^{1}$ is the corresponding coefficient to be estimated. $\vec{C}$ signifies a column vector of variables that describe permanent residents of $n$, such as commuters, as discussed before. These variables are also measured in the unit of households, e.g. the number of households with commuters. $\vec{\beta}^{2}$ is the corresponding row vector of coefficients to be estimated. $\vec{E}$ is a column vector of variables that describe non-permanent residents of $n$ such as 
emigrant workers, again measured in terms of the number of households that e.g. have an emigrated family member. $\vec{S}$ is a column vector of social indicators for entity $n . \vec{G}$ is a column vector of geographic indicators. The term $\beta^{6} \vec{W} \vec{T}$ is a spatial-econometric measure for the interaction with neighbor entities in terms of technology diffusion. $\vec{W}$ is a spatial weighting row vector (with respect to one entity $n$ or a weighting matrix with respect to all entities; cf. LeSage, 1999). $\vec{T}$ is a column vector of technology use (i.e. the number of households that use a technical device) in all other entities that will enter as spatial lags via the weighting vector if they are neighbors of a particular entity $n$. Ignoring spatial correlation in diffusion processes can result in biased results (see the critical discussion by Corrado and Fingleton, 2012). $\vec{D}$ denotes a column vector of measures for existing technologies. $\vec{\beta}^{0}$ is a vector of dummy variables for countries or provinces that may capture unobserved country- or province-specific influences. The residuals are represented by $\epsilon$. This model does not explicitly deal with self-selection, because it looks at the attributes of villages, not the attributes or behavior of persons or households. Furthermore, there is no single, specific explanatory variable under scrutiny, for which self-selection is a relevant issue. The next section will describe the data used for estimating the model parameters in detail.

\section{Empirical analysis of the drivers of mobile phone diffu- siveness in rural Southeast Asia}

This section first describes the data source and the specific indicators that we use. It then describes and discusses the results of the econometric analysis.

\subsection{Data description}

All data used in the following analysis were collected in rural village/household surveys in 2013 based on the DFG ${ }^{1}$ project FOR 756 and related surveys. Our study is one of the first that make use of the most recent survey data for 2013 (data for previous years have been introduced and applied by Hardeweg et al., 2012, 2013). Our study includes for the first time Laos and Cambodia as new areas of research. The new data are consistent with the existing data for Thailand and Vietnam.

Our cross-sectional dataset for the year 2013 encompasses four countries of the Southeast Asian Mekong region: Thailand, Vietnam, Laos and Cambodia. Within each coun-

\footnotetext{
${ }^{1}$ Deutsche Forschungsgemeinschaft, German Research Foundation.
} 
try, the data have been collected in specific provinces: Buriram, Nakhon Phanom and Ubon Ratchathani in Thailand; Dak Lak, Ha Tinh and Thua Thien Hue in Vietnam; Savannakhet in Laos; and Stung Treng in Cambodia. For this analysis, we utilize rural village-level data. Hence, $n$ denotes a specific village of about 500 villages in total. These data have the advantage that detailed geographic information is available. At the village-level, we know, for example, the geographic location of the village, the travel time from each village to the next town in the same province, or the condition of the main road leading to the village. We also know the technology use in neighbor villages and can model technology diffusion across villages. For each village $n$, we know how many households live there, how many households have access to at least one mobile phone, how many households include a commuter, how many households include a worker who emigrated to another country, and so forth. The villages were selected with a threestage stratified random sampling technique (province, district, sub-district) so that each household in the survey had the same probability of being selected for the survey (cf. Hardeweg et al., 2012). The information used in the following analysis was reported by the village head of each community $n$. The choice of each indicator variable will be detailed in the paragraphs below, including information on the countries and provinces in the sample.

We insert the following indicator variables, that are all available within our survey data at the village-level, into the model described by Equation 3. Table 1 depicts the descriptive statistics (mean, standard deviation, minimum, maximum) for the variables of the data sample in the form, in which they are included in the econometric estimation (excluding dummy variables that only take the values zero and one). For variables measured in absolute numbers, the corresponding shares, i.e. the number of households among all households in village $n$, are reported in parentheses in order to make the descriptive statistics more intuitive. The number of households per village varies in the range of 36 to 1132 . The number of households that use mobile phones varies between zero and 792 with a large number of villages with quasi full mobile phone coverage of households. On the contrary, the data report zero or close to zero mobile phone use only for three villages within the whole sample. Eight villages have a share of households with mobile phones below ten percent. This information indicates that almost all villages are at least partly equipped with cell towers for telecommunication services. The average share of households who have access to mobile phones exceeds 90 percent. Nonetheless, the standard deviation of the share of households with mobile phones is 17 percent so that there is significant variation in mobile phone coverage across 


\begin{tabular}{|c|c|c|c|c|}
\hline Variables & Mean & Std. dev. & Min. & Max. \\
\hline hh & 184.10 & 114.81 & 36 & 1132 \\
\hline hh_mphone & 168.47 & 101.51 & 0 & 792 \\
\hline (shr_mphone) & 0.93 & 0.17 & 0 & 1 \\
\hline hh_commute & 10.87 & 19.84 & 0 & 234 \\
\hline (shr_commute) & 0.06 & 0.09 & 0 & 0.99 \\
\hline hh_em_prov_rur & 2.28 & 6.42 & 0 & 62 \\
\hline (shr_em_prov_rur) & 0.01 & 0.02 & 0 & 0.15 \\
\hline hh_em_prov_urb & 3.11 & 9.488 & 0 & 128 \\
\hline (shr_em_prov_urb) & 0.01 & 0.04 & 0 & 0.56 \\
\hline hh_em_coun_rur & 1.46 & 4.28 & 0 & 53 \\
\hline (shr_em_coun_rur) & 0.01 & 0.02 & 0 & 0.24 \\
\hline hh_em_coun_urb & 3.89 & 9.56 & 0 & 157 \\
\hline (shr_em_coun_urb) & 0.02 & 0.05 & 0 & 0.70 \\
\hline hh_em_city & 11.20 & 15.49 & 0 & 92 \\
\hline (shr_em_city) & 0.06 & 0.08 & 0 & 0.66 \\
\hline hh_em_abroad & 1.04 & 3.32 & 0 & 51 \\
\hline (shr_em_abroad) & 0.01 & 0.02 & 0 & 0.23 \\
\hline hh_gov_employ & 12.94 & 21.16 & 0 & 212 \\
\hline (shr_gov_employ) & 0.09 & 0.17 & 0 & 1 \\
\hline hh_agri_work & 18.98 & 40.55 & 0 & 375 \\
\hline (shr_agri_work) & 0.13 & 0.24 & 0 & 1 \\
\hline $\mathrm{hh}$ fforeigners & 0.20 & 0.67 & 0 & 7 \\
\hline (shr_foreigners) & 0.00 & 0.01 & 0 & 0.06 \\
\hline num_enterpr & 0.50 & 4.63 & 0 & 99 \\
\hline size_hhold & 4.56 & 1.20 & 2 & 20 \\
\hline shr_15yr & 0.25 & 0.10 & 0.03 & 0.72 \\
\hline shr_wealthy & 0.07 & 0.09 & 0 & 0.83 \\
\hline geo_access & 4.38 & 1.31 & 1 & 7 \\
\hline road_flaw & 1.86 & 1.07 & 1 & 5 \\
\hline time_prov_town & 69.60 & 50.49 & 1 & 330 \\
\hline dist_sec_school & 3.41 & 6.43 & 0 & 70 \\
\hline dist_bank & 11.01 & 16.53 & 0 & 100 \\
\hline shr_car & 0.12 & 0.18 & 0 & 1 \\
\hline shr_electric & 0.92 & 0.24 & 0 & 1 \\
\hline shr_www & 0.09 & 0.23 & 0 & 1 \\
\hline
\end{tabular}

Table 1: Descriptive statistics of the survey data (excluding dummy variables) encompassing over 500 villages in Thailand, Vietnam, Laos and Cambodia. hh denotes the total number of households in village $n, \mathrm{hh}_{-} \ldots$ signifies the number of households with a specific attribute. For most variables, the number of households is used in the regressions. Then the corresponding share in all households is reported in parentheses. The following abbreviations apply: $\mathrm{hh}=$ number of households, num $=$ number, $\mathrm{shr}=$ share, $\mathrm{em}=$ emigration, prov $=$ province, coun $=$ country, rur $=$ rural, $u r b=$ urban, city $=$ capital city, gov $=$ government, employ $=$ employee, agri $=$ agriculture, work $=$ worker, enterpr $=$ enterprises, hhold $=$ households, $15 \mathrm{yr}=15$ years (or less), geo $=$ geographic, dist $=$ distance, $\sec =$ secondary, electric $=$ electricity, www $=$ world wide web (Internet). 
villages. Consequently, there is still room for technology diffusion. This situation might change during the next years so that almost all households will own a mobile phone. The dependent variable, which appears in the regressions, is the absolute number of households with mobile phones. This absolute number has a standard deviation of over 100 , because it depends on the village size and the village size varies considerably. With respect to emigration, we can compute the number of households that include villagers who emigrated to destinations within the same province, country, and so forth. Although emigration generally does not reduce the total number of households in a village, it does - according to the technology drain hypothesis - reduce the likelihood that a household with emigrants uses a mobile phone.

Our main regressions include the following indicators that describe labor- or business-related connections:

- hh is the total number of households in village $n$, denoted by $P$ in Equation 3 , It is an essential control variable, because it measures village size. Clearly, we expect a positive (proportionate) relation of hh and hh_mphone.

- hh_mphone is a measure for $T$, the spread and use of advanced technologies, which is the dependent variable. More specifically, it signifies the the number of households (hh) in village $n$ that have access to and presumably use at least one mobile phone (cellular phone). Access to, ownership of and use of mobile phones are treated as synonyms throughout the analysis, since they cannot be separated in the data. Notably, it is possible that a household has access to a mobile phone, owned by a relative or friend.

- hh_commute denotes the number of households that include one person who works outside the village and commutes. It is a measure for $C$. This variable as well as the other variables that describe labor mobility or the presence of foreigners have been computed in the following way: the original data contain the number of villagers who commute for each village. Given the total number of villagers in each village, one can compute the share of commuters in all villagers. Multiplying by the total number of households in each village, one obtains the number of households that include commuters for each village. Expressing the variable in terms of households creates an econometric equation with consistent units following the theoretical background derived in the previous sections. While the average share of commuters in the sample is six percent, this variable has very high variation. According to Hypothesis 1, hh_commute is expected to have a positive impact on technology use 
measured by hh_mphone. Herein, it is not observable whether this technology gain effect acts via knowledge spillovers or physical or financial transfers or increased demand for mobile communication.

- hh_em_prov_rur denotes the number of households in $n$ that have one member who migrated to a rural place within the same province to work there. This indicator is one possible measure for $E$. The average share in all households in a village is about one percent, yet the standard deviation is twice the average. According to the technology gain argumentation of Hypothesis 2, we expect a positive impact on hh_mphone. It is again not detectable whether this technology gain effect acts via knowledge spillovers or physical or financial transfers or increased demand for mobile communication. On the one hand, the technology gain effect can be large, because the distance between the new residence and $n$ is relatively small. On the other hand, we expect the technology gain effect to be small, because the new residence is in a rural area with a low technology level. In contrast to this positive effect, the technology drain through migration as formulated in Hypothesis 3 suggests a negative impact of hh_em_prov_rur on hh_mphone. Furthermore, one can expect lower remittances from rural low-income destinations of emigrants than from urban destinations with on average higher income levels. Consequently, the overall impact is ex ante ambiguous.

- hh_em_prov_urb is the same indicator, but with an urban instead of a rural destination of emigrant workers within the same province. It is a measure for $E$, too. Again, the average share in all households in a village is about one percent, while the standard deviation is four times the average. Urban places usually have higher technology levels or densities than rural places. As a consequence, we expect a stronger positive technology gain effect than for hh_em_prov_rur. The low average and high standard deviation also apply to the following two indicators.

- hh_em_coun_rur mirrors hh_em_prov_rur with emigrant workers' destinations in the same country instead of the same province. It is another measure for $E$. Because of the larger distance between $n$ and the destination, we expect that the technology gain effect is weaker than for hh_em_prov_rur, given that technology diffusion progresses decay in distance.

- hh_em_coun_urb corresponds to hh_em_prov_urb with with destinations in the same country instead of the same province. It is a further measure for $E$. We expect 
a stronger positive effect on technology use than for hh_em_coun_rur because of a higher expected technology density in urban than in rural areas.

- hh_em_city, another measure for $E$, mirrors the considerations for hh_em_coun_urb in intensified form, because it considers the capital city of the country as the destination of emigrant workers. We expect that the technology density of the capital city is among the highest in a country so that the positive technology gain effect is supposed to be high. The corresponding share in all households is larger than six percent so that a more significant effect can be expected than for the previous indicators.

- hh_em_abroad goes one step further by looking at destinations abroad as an indicator for $E$. The average share of villagers living abroad amounts to 0.7 percent. Principally, destinations abroad can generate a strong positive technology gain, when the countries abroad have high technology levels. Our data suggest, however, neighbor countries in the Mekong region as destination in many cases. For example, many Laotians migrate to Thailand and send back remittances. Furthermore, the larger distance between the home residence $n$ and the destination might lower technology gains.

- hh_gov_employ describes the number of households $n$ including a government employee. We lack precise information on the place of residence of the government employees. We expect that a large share of them lives in village $n$ so that this indicator can be attributed to $C$. Due to the linkages to outside the village within the governmental administration and their distinguished tasks, we expect a positive association of governmental employees with technology use in accordance with Hypothesis 1.

- hh_agri_work describes the number of households in $n$ who work in the farming sector (not who own a farm). These farmers can be expected to live within the village and to work on the surrounding fields so that this indicator relates to $C$. Farmers likely use mobile devices for work- and business-related communication with each other or with the employer, for example about new jobs or tasks or about crop market prices. Therefore, we expect a positive technology gain effect. Notably, Table 4 reveals a relatively high correlation between commuters and agricultural workers as well as government employees. This tells us something about the profession of commuters by indicating that they often belong to one of 
these two groups.

- hh_foreigners represents the number of households in $n$ who accommodate a foreigner (who are not born in $n$ ). The country-specific term used in the survey forms especially refers to white foreigners, i.e. mostly people from high-income countries. The descriptive statistics tell us that the share of households that host foreigners is only 0.1 percent. Not knowing the home countries of the foreigners, we suppose that they have private or work- or business-related contacts to other countries and cultures and more information about the technologies used there and take technological devices, in this case mobile phones, with them to the village. Hence, we expect a positive a effect of foreigners on technology use. If the foreigners, on the contrary, mainly come from neighbor countries with similar socio-economic and technological characteristics, this positive effect will expectedly vanish. Since the foreigners stay in $n$ at least for some time, we may subsume them under variable $C$.

- num_enterpr denotes the number of enterprises in the village with at least five (for Laos and Cambodia) or nine (for Thailand and Vietnam) employees. Since these enterprises are located within the village, we can also associate them with variable $C$ and expect a positive effect on technology use. The reasoning is that business activities likely exceed the scope of the village and create outward linkages. Additionally, business activities likely require communication technologies.

- vil_project is a dummy variable that takes the value one if there are ongoing cooperative projects together with neighbor villages. Such cooperation improves knowledge linkages and mobile communication between villages and can thus be expected to raise technology use. Since there is no emigration involved, we associate this indicator with variable $C$ as well.

Overall, the share of mobile phone users in villages is high, whereas the shares of specific groups of villagers like emigrant workers are small. Table 4 shows that the correlations between these indicator variables are in most cases relatively low. Nonetheless, we restrict the number of explanatory variables included simultaneously in one regression, because the total number of available observations is around 500. Our dataset does not include information on the telecommunication infrastructure, i.e. the location of cell towers. Therefore, we can only examine the diffusion of mobile phones (cellular phones), not the spread of cell towers and the corresponding cells, which are a prerequisite for the use of mobile phones. We capture the possibility to install telecommunication 
infrastructure implicitly via geographic accessibility and distance measures. We know from our data and our field experience that almost all villages have at least partial access to mobile telecommunication nets and services. Our data do not provide prices for mobile phones or telecommunication services, either. Therefore, we assume that these prices are approximately constant across villages. They can at least be expected to be constant within each country or province, whereby country- or province-specific effects will be taken into account. Technology-related prices will presumably fall over time, yet, we have no time dimension available for our four-country dataset.

In our robustness checks, we add social, geographic, technological as well as countryand province-specific determinants, as outlined in section 3.1. First, we introduce social indicators that are captured by variable $S$ in Equation 3 .

- size_hhold depicts the average number of household members in village $n$. A larger household size increases the likelihood that a mobile phone is used for communication by a household member.

- shr_15yr is the share of villagers in $n$ aged less than 15 years. According to Table 1. on average one quarter of the population belongs this group of young people. This indicator may have a positive impact on mobile phone use due to a high affinity of young people to modern technologies. On the contrary, this indicator may have a negative impact, because young people have zero or low income and can therefore hardly afford electronic devices like mobile phones. Different to the core variables, we insert this indicator in share form into the regression, because the number of households with people aged less than 15 is highly correlated with the number of households, called hh. This will create a collinearity problem when using the number of young people in absolute terms.

- shr_wealthy is the share of households in $n$ who are considered wealthy by the village head. In the absence of an exact income measure at the village-level and without a clear definition of "wealthy" in terms of the minimum income (e.g. measured in dollars), this indicator provides an subjective approximation of the overall affluence of village $n$. According to Table 1 , the share of wealthy people can reach a maximum of more than 80 percent. Nonetheless, the average share reaches less than 7.5 percent. According to this average, the villages under study can be considered as relatively poor - judged from a subjective village-specific perspective. For consistency with shr_15yr, this indicator is used in share form as well. 
A major reason for carrying out the analysis at the village-level is the availability of various geographic indicators, captured by $G$, and the possibility to model technology diffusion across villages from a spatial-econometric perspective, symbolized by $\vec{W} \vec{T}$ in Equation 3. These geographic indicators are related to the labor mobility indicators that we also examine from a spatial perspective by distinguishing migration within the same province, country, rural or urban areas, and so forth. The geographic indicators also measure the possibility to install telecommunication infrastructure, particularly cell towers, in remote rural areas.

- geo_access constitutes a stylized indicator for geographic remoteness, composed by ordering geographic attributes according to the ease of accessibility of villages that they allow. A higher score indicates better accessibility ${ }^{2}$ We expect that better accessibility eases the spread of technologies and thus has a positive impact on technology diffusion. Regarding telecommunication, better geographical conditions ease the installation of cell towers.

- road_flaw depicts another stylized indicator for geographic remoteness composed by ordering the detrimental conditions of the main road to a village with a higher score indicating worse accessibility ${ }^{3}$ This indicator is expected to generate a negative impact on technology diffusion.

- time_prov_town measures the travel time from village $n$ to the next town in the province in minutes. It is a direct distance measure of remoteness. In contrast to the distance measured in kilometres, this time measure takes the travel conditions on the way to the village into account. We expect a negative impact on technology diffusion. (According to Table 5, the correlation between time_prov_town and road_flaw is relatively low so that they can simultaneously appear in a regression.)

- dist_sec_school measures the distance from village $n$ to the nearest secondary school in kilometres. If a secondary school is located within the same village, the indicator takes a value of zero or close to zero. This indicator is a more specific measure of remoteness than time_prov_town. It describes the (inverse) accessibility of (higher) education. Education is supposed to be a basis for knowing about,

\footnotetext{
${ }^{2} 1 \equiv$ mountain, $2 \equiv$ slope, $3 \equiv$ valley, $4 \equiv$ plain, $5 \equiv$ river, $6 \equiv$ lake, $7 \equiv$ coast. The underlying assumption is that better accessibility via the water has historically eased infrastructural connectivity, economic integration and hence economic development.

${ }^{3} 1 \equiv$ two-lane made road, $2 \equiv$ single-lane made road, $3 \equiv$ all-season dirt road, $4 \equiv$ dirt road, seasonally not viable, $5 \equiv$ track, path.
} 
understanding and using advanced technologies. We expect that a larger distance hinders the access to education and hence technology-related knowledge and creates a negative impact. dist_sec_school can also be interpreted in a broader sense as an indicator for infrastructural connectivity. Different to time_prov_town, it measures the distance to a specific infrastructural entity, in this case, the nearest secondary school.

- dist_bank is, analogous to dist_sec_school, another indicator for infrastructural connectivity and hence a specific measure of remoteness. In this case, access to financial services is the relevant aspect. The purchase of a telecommunication device might require a bank loan. In this sense, a larger distance to the next bank hinders technology use and generates a negative effect. A positive effect is also possible, though. The non-availability of a bank provides an incentive to use smartphones that provide access to Internet services including online banking. Lacking in precise statistical information on smartphone use, to our knowledge, Internet access via smartphones is wide-spread in Thailand, but not so in Cambodia, and (online) banking does not play a major role in most rural areas under examination. Hence, the effect of dist_bank is ambiguous or, following the argumentation on dist_sec_school, negative.

- hh_mphone_d represents the term $\vec{W} \vec{T}$ in 3 . It is a spatial-econometric measure for the interaction with neighbor entities in terms of technology diffusion. The weighting vector (or matrix with respect to all entities) $\vec{W}$ contains values of one for neighbor entities, each divided by the total number of neighbor entities of $n$ (cf. LeSage, 1999). By dividing by the number of neighbors, we will in the end obtain the average technology level of neighbor villages. $\vec{T}$ is a column vector of technology use (i.e. the number of households that use a technical device) in all other entities that will enter as spatial lags via the weighting vector if they are neighbors of a particular entity $n$. We treat all villages as neighbors that are located within the same officially (politically) defined district. The multiplying $\vec{W} \vec{T}$ eventually yields the average number of households with mobile phones in villages in the same districts. This average is multiplied by one coefficient, which is to be estimated. In this way, we model rural technology diffusion explicitly in form of spatial correlation. We expect that a larger number of technological devices is neighbor villages creates a positive technology spillover on $n$.

Moreover, we take the impact of existing technologies on the adoption of new technologies 
into account, represented by $D$ in Equation 3 . The prevalence of other technologies is at the same time an indicator for the income level and the stage of economic development of an entity $n$. We compute these indicators in share form to avoid collinearity problems.

- shr_car denotes the share of households who own a car, pick up or truck. From a general perspective, it represents an indicator for an existing technology that may ease the adoption and use of a new technology. We expect a positive relation. From a more specific perspective, the ownership of a car can be interpreted as an indicator for mobility and for relatively high income or affluence. Mobility and affluence can be expected to raise the likelihood of buying a mobile phone.

- shr_electric is the share of households with access to the electricity grid. It is another indicator for existing technologies that may have a positive effect on mobile phone use as well. Access to electricity also indicates an advanced stage of economic development. From a practical perspective, electricity is a requirement for charging a mobile phone. Yet, electricity can also be locally generated. We know from Table 1 that the share of households with electricity access averages around 90 percent. Hence, as for the social indicators, we chose the share form, because the correlation of the number of households with access to electricity in absolute terms with the number of households in the village, denoted by hh, is high. In a broader sense, this indicator measures infrastructure within and across villages, which can be seen as a prerequisite for technology adoption.

- shr_www is the share of households with access to the Internet (via fixed cables or via wireless technologies). As another ICT indicator, it is closely related to mobile phone use. Access to information (and communication) via the Internet and communication via mobile phones are basically complements. Compared to access to electricity, access to the Internet indicates a more advanced stage of economic development and increased income. The descriptive statistics show that the average share of households with Internet access is less than ten percent. Smartphones with Internet capability can also substitute conventional Internet access. According to our experience, Internet access via smartphones is widespread in Thailand, but not so in Cambodia. In a broader sense, this indicator, too, can be seen as a measure for infrastructure.

Because of the limited number of observations, we restrict the number of control variables utilized simultaneously in a regression. We leave out an overall constant throughout our 
regressions, because it lowers the explanatory power of the model substantially. Instead, we introduce country- or province-specific effects captured by $\beta^{0}$ in Equation 3 .

- Thailand, Laos and Cambodia are dummy variables that capture country-specific effects that are not exactly known and specified. (We will exclude the dummy variable for Vietnam as a redundant dummy in the regressions, because it is highly correlated with that for Thailand, cf. Table 5). With respect to gross domestic product per capita, among 184 listed economies in the world (World Bank, 2014), Thailand is ranked 95, Vietnam 137, Laos 151 and Cambodia 153. Laos and Cambodia are labeled least developed countries, whereas Thailand is much more developed. Nonetheless, the Thai provinces under scrutiny are poor provinces as outlined in the following.

- Buriram, Nakhon_Phanom, Ubon_Ratchathani, Dak_Lak, Ha_Tinh, Thua_Thien_Hue, Savannakhet and Stung_Treng symbolize province-wise dummy variable as an alternative to country-wise dummies. Stung Treng is located in the North of Cambodia at the border to Laos. Savannakhet is located in the South of Laos, but not directly at the border to Cambodia. In Thailand, the provinces in the sample are located in the Northeast, which is known as the "poverty pocket" of Thailand (Healy and Jitsuchon, 2007), where rural environments and agriculture still dominate. Ubon Ratchathani at the border to Laos and Cambodia shows significant infrastructural development (cf. Hardeweg et al., 2013). Among the three Vietnamese provinces in the sample, Ha Tinh and Thua Thien Hue are located at the North Central Coast reaching to the border to Laos, whereas Dak Lak is landlocked in the Central Highlands at the border to Cambodia. Agriculture plays an important role in the Vietnamese provinces, although Hue is economically more diversified including tourism and fishery (cf. Hardeweg et al., 2013). In Dak Lak, cash crops play a major, whereas in the other Vietnamese provinces subsistence farming prevails.

Table 5 in the Appendix displays the correlation matrix for the regressors of the robustness check (excluding the various province-specific dummy variables). The full correlation matrix including all control variables goes beyond the scope of a printable page, but is available upon request. This completes the description of the variables used in our regression analysis. 


\subsection{Econometric results}

This section discusses the results of the basic regressions and the robustness check regressions based on Equation 3

Table 2 reports the main regression results of the linear Ordinary Least Squares estimations in form of the estimated coefficients, heteroscedasticity robust p-values in parentheses and the corresponding significance levels indicated by stars. The adjusted $\mathrm{R}^{2}$ values are about 0.96 , which indicates high explanatory power of the model. This high explanatory power can be achieved, because the number of households with mobile phones in a village (hh_mphone) is highly correlated with the total number of households in a village (hh) so that hh explains a large part of the variation in the dependent variable, hh_mphone.

The coefficient estimated for the number of households, hh, is always highly significant and positive. The positive value implies that the number of households with access to mobile phones and hence technology use increase in the number of households. Leaving aside the consecutive determinants, its value of around 0.85 means that on average 85 percent of households have access to mobile phones. This straightforward interpretation follows from the consistent measurement of variables in the unit number of households as far a possible.

The coefficient of hh_commute is always positive and in half of the regressions statistically highly significant. This result confirms the technology gain Hypothesis 1 . The coefficient's value of 0.15 is also economically significant: 100 households with commuters result in 15 households with mobile phone users. Obviously, many commuters are governmental employees or agricultural workers. This is also reflected by the relatively high correlation between hh_gov_employ, hh_agri_work and hh_commute in Table 4 in the Appendix. Consequently, the coefficient for commuters turns insignificant once governmental employees and agricultural workers are included in regressions (2) to (4).

The coefficient of hh_em_prov_rur is always negative and in most cases at least significant at the ten percent significance level and has a high magnitude of around -0.6. This result confirms the technology drain Hypothesis 3. It implies that the technology drain dominates the technology gain effect. This result is also in line with Hypothesis 2c, stating that the technology gain is low for rural destinations.

The coefficients of hh_em_prov_urb, on the contrary, is always insignificant. One can argue that the technology drain and the technology gain effect balance each other. This would be in line with Hypothesis 2c: now the technology gain effect is stronger than in 
(1)

(2)

(3)

(4)

(5)

(6)

Variables

hh_mphon

hh_mphone

hh_mphone

hh_mphone

hh_mphone hh_mphone

hh

$0.87^{* * *}$

$0.86^{* * *}$

$0.85^{* * *}$

$0.85^{* * *}$

$0.86^{* * *}$

$0.83^{* * *}$

(0)

(0)

hh_commute

$0.15^{* * *}$

0.073

(0)

(0)

(0)

(0)

(0.0019)

(0.35)

hh_em_prov_rur

$-0.66^{* *}$

$-0.57^{*}$

0.0074

0.0018

$0.15^{* * *}$

$0.19^{* * *}$

(0.050)

(0.074)

(0.93)

(0.98)

(0.0016)

(0.00034)

$-0.53^{*}$

$-0.51$

$-0.62^{*}$

$-0.40$

hh_em_prov_urb

$-0.12$

(0.095)

(0.11)

$(0.063)$

$(0.73)$

(0.58)

$-0.051$

$-0.059$

$-0.084$

$-0.042$

(0.77)

(0.68)

(0.82)

hh_em_coun_rur

$-0.89$

$-0.85$

$-0.95$

$-0.93$

$-0.93$

(0.21)

$(0.23)$

$(0.25)$

$(0.21)$

$(0.20)$

(0.16)

$-0.098$

$-0.094$

$-0.17$

$-0.14$

(0.25)

hh_em_city

$0.63^{* * *}$

(0.44)

(4.7e-06)

(0.54)

$0.63^{* * *}$

(0.56)

$0.59^{* * *}$

(0.26)

(0.32)

$0.64^{* * *}$

(6.0e-06)

(0.000013)

$0.63^{* * *}$

$0.46^{* * *}$

hh_em_abroad

$-0.23$

$-0.21$

(0.69)

$-0.24$

$-0.22$

(4.1e-06)

(0.000062)

(0.67)

(0.65)

(0.68)

$0.17^{*}$

0.13

$(0.74)$

$-0.24$

(0.100)

(0.19)

0.12

$0.087^{* *}$

$(0.21)$

(0.021)

$0.083^{* *}$

(0.027)

$4.43^{* * *}$

(0.0012)

(0.64)

hh_foreigners

num_enterpr

vil_project

(0.00028)

$15.8^{* * *}$

$(0.00029)$

\begin{tabular}{lcccccc} 
Observations & 508 & 496 & 496 & 496 & 508 & 481 \\
Adj. $\mathrm{R}^{2}$ & 0.961 & 0.961 & 0.961 & 0.961 & 0.962 & 0.963 \\
\hline
\end{tabular}

Robust p-values in parentheses:

*** $\mathrm{p}<0.01,{ }^{*} * \mathrm{p}<0.05, * \mathrm{p}<0.1$

Table 2: Main regression results. The number of households that have access to mobile phones within Southeast Asian villages in the year 2013 explained by labor- and businessrelated determinants that are in most cases measured as the number of households with specific attributes.

case of hh_em_prov_rur because of the urban destination. One can also argue that none of the effects, technology gain or drain effect, shows up significantly. Consequently, no clear result can be formulated with respect to the hypotheses under scrutiny.

hh_em_coun_rur, hh_em_coun_urb and hh_em_abroad are never significant, either. This means, we cannot detect a difference between destinations in the same province, in the same country and abroad. Therefore, the results are inconclusive with respect to role of the distance between the home village and the destination of emigrant workers 
as formulated in Hypothesis 2b. The insignificant effect of hh_em_abroad might indicate that emigrant workers often move to neighbor countries with similar technology levels, not to industrialized high-tech countries, so that technology spillovers are weak. Overall, this result indicates that there is no clear relation between the migration distance and the resulting technology-related connections. This result is in accordance with the ambiguous role of the migration distance that be identified in our theoretical considerations.

The coefficient of hh_em_city is always highly significant and positive with a similar magnitude as the negative effect of hh_em_prov_rur. This positive effect is in accordance with the technology gain Hypothesis 2c that suggests a stronger positive effect for urban destinations with higher technology levels than for rural destinations with lower technology levels. Possibly, migrants residing in the (capital) city have better access to cheaper new technologies than people residing in villages and send, for instance, mobile devices to their relatives and friends residing in villages in form of non-monetary remittances. Alternatively, they might send monetary remittances. Our village-level data, however, do not allow this distinction.

Besides these labor migration variables, we look at further variables that describe labor- and business-related connections. hh_gov_employ is only in regression (2) weakly significant and positive. This means, governmental employees enhance technology use as expected and in accordance with Hypothesis 1. The magnitude of this effect is similar to the effect of commuters on technology use. Yet, the statistical significance is weak.

hh_agri_work enters with a significantly positive coefficient. Though, the magnitude of this coefficient is clearly smaller than that of the other coefficients.

hh_foreign has a highly significant, positive as expected and, compared to the other coefficients discussed so far, very large coefficient. Since this result lacks in robustness across other specifications, it should be taken with caution. Notwithstanding, a look at the descriptive statistics in Table 1 provides a possible explanation for this result: the number of households with foreigners has a maximum of seven. Hence, if an impact of such a small number can be measured at the village-level, the impact must be large. This result corroborates Hypothesis 1 in the sense that the presence of foreigners enhances technology diffusion.

As expected, num_enterpr has a highly significant and positive coefficient as well. The economic magnitude is not directly comparable to the remaining coefficients, because num_enterpr is not measured in terms of households, but as the number of enterprises in the village. The number of enterprises reaches almost 100 according to Table 1 . 
In this respect, num_enterpr is comparable to hh_em_city, for which the number of households reaches almost 100. Based on this argumentation, the presence of enterprises creates a relatively strong positive impact on technology use. This result corroborates Hypothesis 1 in the sense that business activities enhance technology diffusion. This result will, however, be rebutted by the resampling robustness checks described in the next subsection.

vil_project is a dummy that indicates the existence of any cooperative project with neighbor villages. Based on the highly significant estimated coefficient, we can argue that the existence of cooperative projects in a village results on average in about 16 additional households that use mobile phones. We can hence argue that connections with neighbor villages enhance rural technology diffusion in the sense of Hypothesis 1.

Table 3 reports the results of the robustness checks, in which we subsequently add social, geographic, technological, country- and province-specific explanatory variables to the indicators for labor mobility in the main regressions as reported by Table 2 . In column (6), we also include remaining indicators for work, business relations and economic projects that appear in Table 2. In order to check whether these indicators are subject to country-specific differences, we add country-specific dummy variables. In order to avoid collinearity, we move the indicator that describes the presence of enterprises to column (7) with province-specific dummies.

The robustness check results corroborate the main regression results for the core variables. The significantly positive effect of commuters is confirmed in all but one regressions. The significantly negative impact of emigrants to rural places in the same province is confirmed in four of seven regressions. Emigrant workers with the capital city as the destination have a positive and highly significant impact on mobile phones throughout all regressions. The significantly positive impact of enterprises holds when controlling for province-specific effects. The positive impact of governmental employees and of foreigners fall below the ten percent level when controlling for country-specific effects. The significantly positive effect of village projects on technology use holds when controlling for country-specific effects. The positive effect of enterprises becomes highly significant when controlling for province-specific effects.

Additionally, the results reveal a significant impact of part of the social, geographic, technological, country- and province-specific explanatory variables as determinants of mobile phone use in Southeast Asian villages. This will be detailed in the following.

Among the social indicators analyzed in column one, size_hhold enters with a highly 


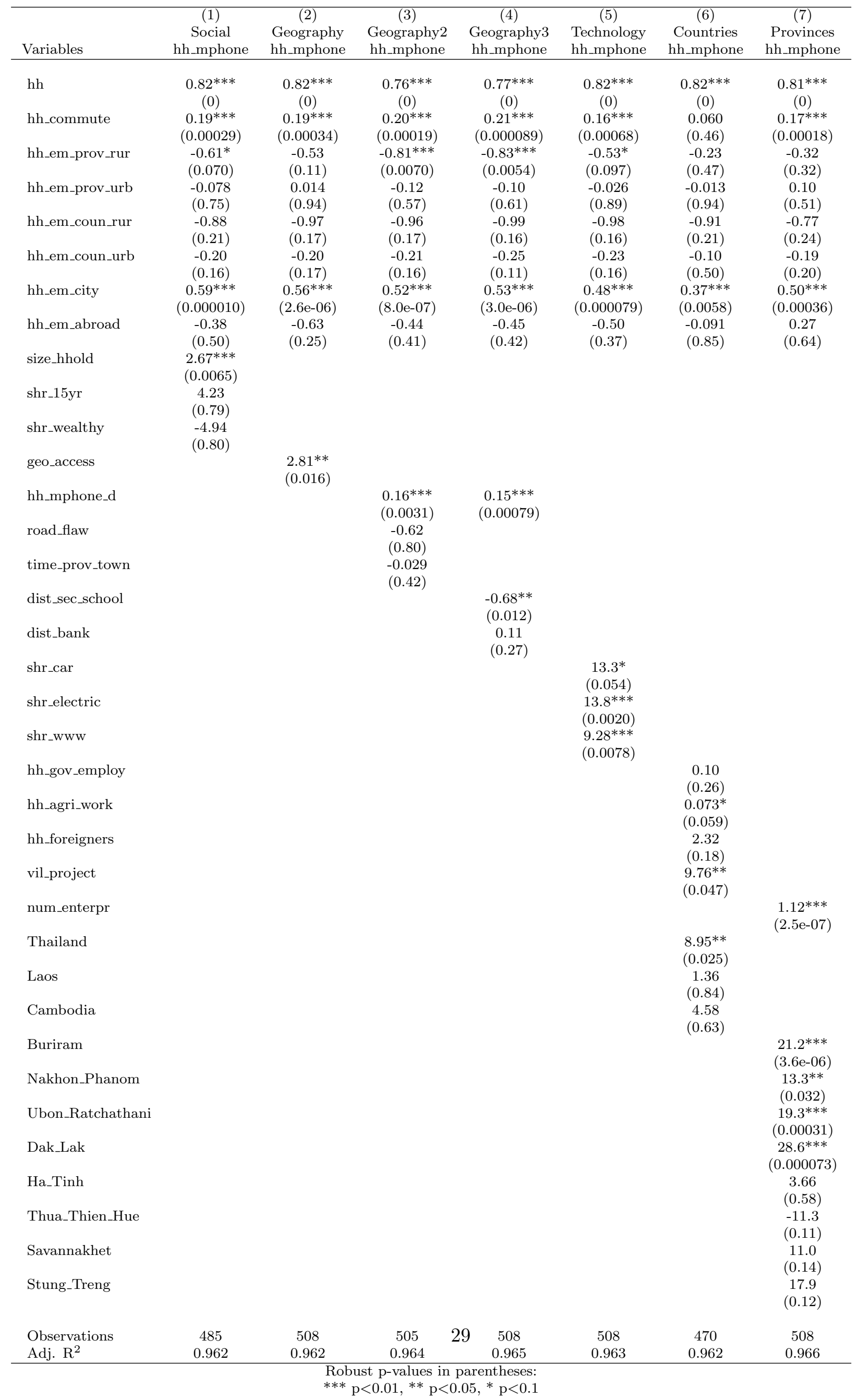

Table 3: Robustness check results for rural mobile phone use in 2013. 
significant and positive coefficient as expected. The economic magnitude of this effect is hardly comparable to the other effects, because size_hhold is measured in terms of the average number of villagers per household. shr_15yr, the share of young people aged 15 years or less, does not have a significant impact on mobile phone use. This result is in accordance with the theoretical ambiguity of this indicator (lower income, but higher technology affinity). The share of wealthy households in a village, shr_wealthy, does not show a significant effect, either. This result is surprising, because we expect a relation between the availability of financial resources and the acquisition of electronic devices. Recalling that the average share of wealthy households in a village is less than ten percent, this share might be too small to have a significant impact at the villagelevel. Furthermore, this indicator builds on a subjective, village-specific view of poverty and wealth, which does not provide a fully-fledged measure of income. Nonetheless, our result is in accordance with the mixed results in the literature. Dasgupta et al. (2005) also find that income seems not to matter for the digital divide. Our result also suggests that geographic or technological aspects create more severe obstacles to technology diffusion than social aspects. Future research could use more detailed wealth or income measures to shed more light on this aspect. More detailed indicators for income and finance are available at the household-level, but not at the village-level with a focus on geographic aspects.

Because the number of observations and overlaps of the statistical and economic meaning of the geographic regressors limit the number of control variables to be included at once, we distribute the geographic indicators across three regressions reported in columns two to four. geo_access entails a significantly positive effect on technology diffusion in form of mobile phone use as expected. This positive effect of geographic accessibility is not supported by road_flaw and time_prov_town, which measure the accessibility of a village via roads, since the estimated coefficients are insignificant. dist_bank, a specific measure for accessibility that refers to access to financial services, does not entail a robust, significant effect on technology use, either. Together with the insignificant effect of hh_wealthy, this result provides some indication for the view that financial restrictions and opportunities are not the major determinants of rural mobile phone use. Notwithstanding, dist_sec_school, the distance to the next secondary school, has a significantly negative impact on mobile phone use as expected. This relation turns out to be robust across different specifications. This result supports the view that education improves the absorptive capacity with respect to the utilization of advanced technologies. It also indicates that schools enhance the knowledge about and the use of modern 
communication devices. (The economic magnitude of this effect is not comparable to the other effects, because dist_sec_school is measured in kilometres.) These results confirm the relevance of geographic aspects for technology diffusion and add new insights, particularly that it matters how we measure distance and accessibility. In this respect, our data sample provides a valuable set of various geographic indicators.

The spatial lag variable, hh_mphone_d deserves special attention. The highly significant and positive coefficient of 0.15 or 0.16 implies that the average number of households with mobile phones in villages within the same district spills over to the number of households with mobile phones in the village under scrutiny by about 15 percent. This important result provides evidence for the existence of technology diffusion processes across villages. It is in line with the spatial-econometric literature on diffusion processes discussed before. It is a novelty to show that such technology diffusion processes can be measured across villages in a rural, developing region, in particular in the Mekong region.

As expected, the three measures for existing technologies, shr_car, shr_electric and shr_www, have a positive impact on mobile phone use. This result is in line with the previous finding of the literature that existing technologies, more specifically ICTs, complement and ease the adoption of new ICTs (in the sense of improved absorptive capacity). Furthermore, access to electricity or the Internet are measures for infrastructural quality, which entails a positive impact on technology diffusion as expected. The result for shr_car adds a new flavor: the ownership of a car can be interpreted as an indicator for mobility, furthermore for relatively high income. In this sense, it is intuitive that persons who are mobile and relatively affluent require and can afford mobile phones. Notably, all our indicators of existing technologies also measure the stage of economic development and the income level. Interpreting the results in this way, we find that a higher stage of economic development and income foster technology use.

Among the country-specific effects, only the dummy variable for Thailand is significant. This result contradicts the view that country differences are a dominant driver of the econometric results. Nonetheless, the positive impact of governmental employees and foreigners fall below the ten percent significance level when controlling for country-specific effects. The significantly positive coefficients of agricultural workers and village projects are confirmed. Among the province-specific dummy variables, half of them has a significant impact on mobile phone use. The regression with province-specific dummies confirms the positive impact of enterprises on technology use, which will be questioned in the following subsection. 
Since we cannot distinguish between no mobile phone access and no availability of telecommunication net and services, we perform the following reduced sample robustness check. We observe three villages with a number of households with mobile phones of zero or almost zero. In these villages, there is likely no telecommunication net available. Therefore, we remove these entries from the data sample and rerun the main regressions as well as the robustness check regressions with additional control variables. The results are reported in a supplementary appendix. We observe the following qualitative differences compared to Table 2. hh_em_prov_rur is now significant in all regressions, whereas hh_gov_employ falls slightly below the ten percent significance level. hh_gov_employ is not significant in the robustness check regressions with additional control variables in the original or the reduced sample, either. Moreover, we observe the following qualitative differences compared to Table 3, hh_agri_work and vil_project fall slightly below the ten percent significance level. Notwithstanding, the travel time to the next town in the province, time_prov_town, becomes significant and has the expected negative sign. This means, a longer travel time hinders technology diffusion as expected.

\subsection{Bootstrap and jackknife estimations}

Our analysis is subject to two general caveats that we address in an extended robustness check that makes use of resampling techniques. First, we estimate a number of coefficients with 500 observations and in some cases with limited variation in the data. To address this issue, we generate for each regression 1000 random drawings (replications) by using the bootstrapping method (cf. Efron, 1979). The results of the main regressions and the robustness check regressions, each with bootstrapped p-values (standard errors), are reported in a supplementary appendix. The bootstrapped main regression results differ in the respect that significance levels are slightly lower, particularly with respect to commuters and emigrants to rural areas in the same province. Nonetheless, the previous results for the role of labor mobility are overall confirmed. The significance level for governmental employees falls below the ten percent threshold, though. The major difference of the bootstrapped main regression results to the previous results is that the high significance of the number of enterprises in a village clearly vanishes. The bootstrapped robustness check results with social, geographic and technological regressors qualitatively hardly differ from the standard robustness check results reported in Table 3, either. The major difference is again the insignificance of the coefficient for the number of enterprises, which is highly significant in Table 3 . 
Second, our survey data might be subject to reporting errors in form of outliers that bias the results. This aspect can be better addressed by using the jackknife method (cf. Tukey, 1958; Mosteller and Tukey, 1977). Therefore, the results of the main regressions and the robustness check regressions with jackknifed p-values (standard errors) are reported in the supplementary appendix as well. Like the bootstrapped p-values, the jackknifed p-values are slightly lower than in the standard main regressions. This particularly slightly reduces the significance of commuters and emigrants to rural areas in the same province. As before, the significance level for governmental employees falls below the ten percent threshold, and the high significance of the number of enterprises in a village clearly vanishes. Against this backdrop, the impact of the presence of enterprises in a village on technology use is questionable and might be driven by outliers. Additionally, the p-value for agricultural workers falls to eleven percent in the jackknife results.

Furthermore, the significance of some results might suffer from the in some cases small shares of specific groups of villagers within the village population. In particular, emigrants to rural or urban destinations within the same country constitute only one percent of the households in a village each and fail to generate a significant effect throughout the regressions. Notwithstanding, their p-values are in several regressions not far away from being significant at the ten percent level. Against this backdrop, future research can try to clarify these so far insignificant effects once a larger number of observations will be available.

\section{Conclusion}

We have developed a new concept of rural technology diffusion with labor mobility and business relations as key determinants. We have defined the technology gain effect as the increase in technology use via knowledge spillovers or physical or financial transfers. We have defined the technology drain effect as a decrease in technology use via the emigration of technology-using residents. Our concept includes social and geographic attributes as well as existing technologies as further determinants. The concept has been applied to village-level survey data from the Mekong region. We have used village-level data in order to focus on the geographic dimension of technology diffusion. Therein, technology use is measured as the number of households in a village that have access to mobile phones.

Following the literature (Buys et al., 2009), we identify technology diffusion in form 
of significant spatial correlation. It is a novelty of our study to show that technology diffusion processes can be measured across villages in a rural, developing region, in this case in the Mekong region. The results show that the geographic accessibility of villages, for example via rivers, lakes or the sea, eases technology diffusion. The closeness of schools also eases technology diffusion. This result can be interpreted in the way that education is important for creating knowledge (flows) and for absorbing technologies (in accordance with Kiiski and Pohjola, 2002, when taking into account developing countries; unlike Baliamoune-Lutz, 2003). It can also be interpreted in the way that infrastrutural connectivity matters for technology diffusion in rural, developing areas. In our regressions, the distance to the next bank or the next town or the condition of the main road leading to a village, however, fail to generate a significant effect on technology diffusion. In some of our regression, a longer travel distance to the next town in the province reduces technology use (like the finding by Buys et al., 2009, that a longer distance to the next main road or city hinders cell tower installations). These results suggest in summary that insufficient accessibility of villages due to geographic obstacles or far distances hinders technology diffusion.

Whereas a larger average family size raises technology use, it is surprising that the age and income structure of villages do not significantly matter for technology use in our regressions (in accordance with the ambiguous role of income in Dasgupta et al., 2005 ; in contrast to the positive impact of income on ICT use found by BaliamouneLutz, 2003). We find a positive impact of existing technologies, i.e. access to electricity and the Internet and cars, to the adoption of further technologies, in this case mobile phones. In this sense, the technologies under scrutiny, including ICT, act as complements (in accordance with Girma, 2005, who studies foreign direct investment; unlike the conclusion of Kamssu, 2005, that mobile phone use grows faster in poor countries where Internet access is low; unlike the view of Dechezleprêtre et al., 2013, who examine patents and find that technologies act as substitutes; and unlike the classic view that a larger technology gap between the technology in practice and the new technology enhances technology diffusion). Access to electricity and the Internet can also be interpreted as an indicator for infrastructural quality within and across villages, which is expected to foster technology diffusion. From a more general perspective, all our indicators of existing technologies measure the stage of economic development and the income level. In this sense, we find that a higher stage of economic development and income foster technology use.

Notably, our results identify a novel economic mechanism that can help overcome 
the geographic obstacles that remote villages are confronted with: labor mobility and business relations can promote technology diffusion and hence foster economic development. This economic channel is not straightforward, though: the econometric results support the technology drain hypotheses. This means, the absence of technology-using emigrant workers can reduce technology use in their home village. This effect is not observed for commuters who come back to their home village every night. Hence, in case of commuters, the technology gain effect dominates. This means, commuters, who are often governmental employees or agricultural workers, enhance technology use in their home villages. The results also show that for urban destinations of migration the technology gain effect likely prevails, whereas for rural destinations the technology drain effect prevails. This may have at least two reasons: first, the prevalence of advanced technologies is lower in rural than in urban destination so that the flow of technological knowledge or devices is limited. Second, the income level is lower so that monetary remittances or non-monetary remittances in form of technological devices are limited. The results are inconclusive with respect to the role of the distance between the home village of emigrant workers and their destinations, though. This indicates, in accordance with our theoretical considerations, that there is no clear-cut relation between the migration distance and the resulting technology-related connections. Furthermore, the presence of foreigners in a village as well as joint projects with neighbor villages seem to have a positive impact on technology use in the village. This indicates that contacts to people from outside the village or outside the country might strengthen technology-related information flows. These findings broaden the scope of our analysis from labor mobility to business relations and socio-economic relations as a determinant of technology diffusion. The positive impact of enterprises on technology use found in the standard regressions is questioned by the bootstrapped and jackknifed robustness check results, though.

In conclusion, the results highlight that labor mobility and business relations can help overcome geographic obstacles to rural development via technology diffusion. The insights are relevant for development programmes that support the access to and spread of ICT among the poor. While the first generation of mobile phones is already widespread in developing countries today, the second generation of smartphones, tablets and the like is not. The latter electronic devices open up a new universe of information, which can be accessible to everyone in the world. After the right to have access to food, clean water, sanitation and education, the right to have access to information will become crucial in the future. In this sense, our results hopefully help overcome the digital divide between rich and poor. 
Apart from the tremendous social problems that rural-urban migration creates in and around cities in developing countries, this study also highlights that a positive economic spillover from urban to rural areas exists. These results provide an important argument for development policy that targets at the enhancement and flexibility of economic activity in rural areas of developing countries.

Our analysis, however, leaves open whether rural technology diffusion is driven by knowledge flows, by physical flows of technical devices, by financial flows (remittances) that in turn enable the acquisition of technical devices, or by an increased demand for mobile communication between village residents and villagers on the move (cf. the anecdotic evidence reported by Paragas, 2010, and Hahn and Kibora, 2008). Future research could improve on this by using individual household-level data that include more precise measures for income and financial flows than the village-level data. Householdlevel survey data might also be more accurate than village-level data. Certainly, data at the individual household-level will increase the number of observations and can therefore improve the significance of the results. Geographic attributes and connections, on the contrary, are not available at the household-level. Our analysis leaves open, too, whether technologies like mobile phones also foster labor mobility. Panel data with more data waves could help shed light on this aspect. Finally, our data reveal a surprisingly high coverage of Southeast Asian villages with mobile phones and a large number of villages, in which quasi every household has access to a mobile phone. This indicates that in the near future mobile phone use will be normal, even in poor rural societies, so that research into mobile phone use will be less fruitful.

\section{Acknowledgment}

We acknowledge financial support by the German Research Foundation (DFG) within the project FOR 756. I am very grateful to Rebecca Hartje for her great help and to Susan Steiner and Lena Hohfeld for very helpful comments. I thank Ulrike Grote and Hermann Waibel for their support.

\section{References}

Baliamoune-Lutz, M. (2003). An analysis of the determinants and effects of ICT diffusion in developing countries. Information Technology for Development 10, 151-169.

Banerjee, A. and A.J. Ros (2004). Patterns in global fixed and mobile telecommunications development: a cluster analysis. Telecommunications Policy 28, 107-132. 
Berger, T. (2001). Agent-based spatial models applied to agriculture: a simulation tool for technology diffusion, resource use changes and policy analysis. Agricultural Economics 25, 245-260.

Buys, P., S. Dasgupta and T.S. Thomas (2009). Determinants of a Digital Divide in Sub-Saharan Africa: A Spatial Econometric Analysis of Cell Phone Coverage. World Development 37(9), 1494-1505.

Besley, T. and A. Case (1993). Modeling Technology Adoption in Developing Countries. American Economic Review, Papers and Proceedings 83(2), 396-402.

Chinn, M.D. and R.W. Fairlie (2007). The determinants of the global digital divide: a cross-country analysis of computer and internet penetration. Oxford Economic Papers $59(1), 16-44$.

Commander, S., M. Kangasniemi and L.A. Winters (2004). The Brain Drain: Curse or Boon? A Survey of the Literature. In: R.E. Baldwin and L.A. Winters (eds.), Challenges to Globalization: Analyzing the Economics, University of Chicago Press, USA, 235-278, http://papers.nber.org/books/bald04-1 (accessed 04/2014).

Corrado, L. and B. Fingleton (2012). Where is the Economics in Spatial Econometrics? Journal of Regional Science 52(2), 210-239.

Doss, C.R. (2006). Analyzing technology adoption using microstudies: limitations, challenges, and opportunities for improvement. Agricultural Economics 34(3), 207-219.

Dasgupta, S., S. Lall and D. Wheeler (2005). Policy Reform, Economic Growth and the Digital Divide. Oxford Development Studies 33(2), 229-243.

Dechezleprêtre, A., M. Glachant and Y. Ménière (2013). What Drives the International Transfer of Climate Change Mitigation Technologies? Empirical Evidence from Patent Data. Environmental and Resource Economics 54, 161-178.

Du, L., A. Harrison and G.H. Jefferson (2012). Testing for horizontal and vertical foreign investment spillovers in China, 19982007. Journal of Asian Economics 23(3), 234-243.

Efron, B. (1979). Bootstrap methods: Another look at the jackknife. Annals of Statistics 7, 1-26.

Girma, S. (2005). Absorptive capacity and productivity spillovers from FDI: a threshold regression analysis. Oxford Bulletin of Economics and Statistics 67(3), 281-306.

Hahn, P. and L. Kibora (2008). The domestication of the mobile phone: oral society and new ICT in Burkina Faso. The Journal of Modern African Studies 46(1), 87-109.

Hardeweg, B., S. Klasen and H. Waibel (2012). Establishing a database for vulnerability assessment. In: Klasen, S. and H. Waibel (eds.), Vulnerability to Poverty: Theory, Measurement and Determinants, with Case Studies from Thailand and Vietnam, 50-79, Palgrave Macmillan, Hampshire, UK. 
Hardeweg, B., A. Wagener and H. Waibel (2013). A distributional approach to comparing vulnerability, applied to rural provinces in Thailand and Vietnam. Journal of Asian Economics 25, 53-65.

Harris, J.R. and M.P. Todaro (1970). Migration, Unemployment and Development: A Two-Sector Analysis. American Economic Review 60(1), 126-142.

He, X. and Q. Mu (2012). How Chinese firms learn technology from transnational corporations: A comparison of the telecommunication and automobile industries. Journal of Asian Economics 23(3), 270-287.

Healy, A.J. and S. Jitsuchon (2007). Finding the poor in Thailand. Journal of Asian Economics 18, 739-759.

Heeks, R. (2010). Do Information and Communication Technologies (ICTs) Contribute to Development? Journal of International Development 22, 625-640.

Hilbert, M. (2010). When is Cheap, Cheap Enough to Bridge the Digital Divide? Modeling Income Related Structural Challenges of Technology Diffusion in Latin America. World Development 38(5), 756-770.

Horst, H. and D. Miller (2005). From Kinship to Link-up - Cell Phones and Social Networking in Jamaica. Current Anthropology 46(5), 755-778.

Howard, P.N. and N. Mazaheri (2009). Telecommunications Reform, Internet Use and Mobile Phone Adoption in the Developing World. World Development 37(7), 1159-1169.

Hübler, M. and A. Keller (2010). Energy Savings via FDI? Empirical Evidence from Developing Countries. Environment and Development Economics 15(1), 59-80.

Jensen, R. (2007). The Digital Provide: Information (Technology), Market Performance, and Welfare in the South Indian Fisheries Sector. Quarterly Journal of Economics 122(3), 879-924.

Kamssu, A.J. (2005). Global connectivity through wireless network technology: A possible solution for poor countries. International Journal of Mobile Communications $3(3), 249-262$.

Keller, W. (2004). International technology diffusion. Journal of Economic Literature $42(3), 752-782$.

Kiiski, S. and M. Pohjola (2002). Cross-country diffusion of the Internet. Information Economics and Policy 14, 297-310.

Kretschmer, B., M. Hübler and P. Nunnenkamp (2013). Does Foreign Aid Reduce Energy and Carbon Intensities of Developing Economies? Journal of International Development 25(1), 67-91.

Kuznetsov, Y., ed. (2006). Diaspora Networks and the International Migration of Skills How Countries Can Draw on Their Talent Abroad. The World Bank, Washington, DC, USA. 
LeSage, J.P. (1999). The Theory and Practice of Spatial Econometrics. Department of Economics University of Toledo, http://www.spatial-econometrics.com/html/ sbook.pdf (accessed 04/2014).

Mazumdar, J. (2001). Imported Machinery and Growth in LDCs. Journal of Development Economics 65(1), 209-224.

Minges, M. (1999). Mobile cellular communications in the Southern African region. Telecommunications Policy 23, 585-593.

Mosteller, C.F. and J.W. Tukey (1977). Data Analysis and Regression: A Second Course in Statistics. Pearson, London, UK, New York, USA.

Muto, M. and T. Yamano (2009). The Impact of Mobile Phone Coverage Expansion on Market Participation: Panel Data Evidence from Uganda. World Development 37(12), 1887-1896.

Nelson, R. and E. Phelps (1966). Investment in humans, technological diffusion, and economic growth. American Economic Review, Papers and Proceedings 61, 69-75.

Paragas, F. (2010). Migrant Workers and Mobile Phones: Technological, Temporal, and Spatial Simultaneity. In: R. Ling and S.W. Campbell (eds.), The Reconstruction of Space and Time - Mobile Communication Practices, Transaction Publishers, New Brunswick, New Jersey, USA, 39-66.

Richards, T.J., S.F. Hamilton and W.J. Allender (2014). Social Networks and Product Choice. American Journal of Agricultural Economics 96(2), 489-516.

Saggi, K. (2002). Trade, foreign direct investment, and international technology transfer: a survey. World Bank Research Observer 17(2), 191-235.

Tukey, J.W. (1958). Bias and confidence in not-quite large samples. Annals of Mathematical Statistics 29, 614 .

World Bank (2014). World Development Indicators. The World Bank, Washington, DC, USA, http://data.worldbank.org/data-catalog/world-development-indicators (accessed 04/2014).

$\mathrm{Xu}, \mathrm{X}$. and Y. Sheng (2012). Are FDI spillovers regional? Firm-level evidence from China. Journal of Asian Economics 23(3), 244-258.

\section{Appendix}


hh hh_com hh_em_pr_r hh_em_pr_u hh_em_co_r hh_em_co_u hh_em_city hh_em_ab hh_gov_em hh_agr_work hh_for num_ent vil_proj

\begin{tabular}{|c|c|c|c|c|c|c|c|c|c|c|c|c|c|}
\hline hh & 1 & & & & & & & & & & & & \\
\hline hh_commute & 0.4125 & 1 & & & & & & & & & & & \\
\hline hh_em_prov_rur & 0.3554 & 0.175 & 1 & & & & & & & & & & \\
\hline hh_em_prov_urb & 0.3524 & 0.2033 & 0.2262 & 1 & & & & & & & & & \\
\hline hh_em_coun_rur & 0.191 & 0.1025 & 0.0941 & 0.1232 & 1 & & & & & & & & \\
\hline hh_em_coun_urb & 0.1709 & 0.1141 & 0.0481 & 0.0834 & 0.0889 & 1 & & & & & & & \\
\hline hh_em_city & 0.2975 & 0.1495 & 0.0951 & 0.1181 & 0.0166 & 0.2209 & 1 & & & & & & \\
\hline hh_em_abroad & 0.09 & 0.0101 & 0.0112 & 0.122 & 0.0396 & 0.0225 & -0.0359 & 1 & & & & & \\
\hline hh_gov_employ & 0.44 & 0.6589 & 0.0897 & 0.2774 & 0.0905 & 0.0178 & 0.1334 & 0.0314 & 1 & & & & \\
\hline hh_agri_work & 0.3197 & 0.5537 & 0.0673 & 0.0492 & 0.0343 & 0.0113 & 0.1036 & 0.0098 & 0.4798 & 1 & & & \\
\hline hh_foreigners & 0.0307 & 0.1639 & -0.0308 & 0.0591 & 0.1377 & 0.0189 & 0.1718 & -0.0471 & 0.1509 & 0.1232 & 1 & & \\
\hline num_enterpr & 0.1747 & 0.3204 & 0.01 & 0.137 & 0.0168 & 0.0425 & 0.0114 & -0.0203 & 0.2269 & 0.1998 & 0.0234 & 1 & \\
\hline vil_project & -0.1111 & -0.0612 & -0.1136 & -0.0116 & -0.0155 & -0.0337 & 0.1876 & -0.0436 & 0.0635 & 0.0249 & 0.0853 & 0.0165 & 1 \\
\hline
\end{tabular}

Table 4: Correlation matrix for the core variables. 


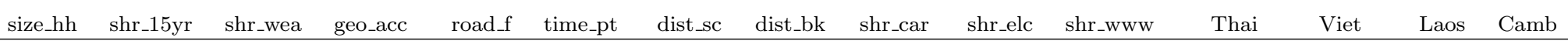

\begin{tabular}{|c|c|c|c|c|c|c|c|c|c|c|c|c|c|c|c|}
\hline & size_hh & shr_15yr & shr_wea & geo_acc & road_f & time_pt & dist_sc & dist_bk & shr_car & shr_elc & shr_www & Thai & Viet & Laos & Camb \\
\hline size_hhold & 1 & & & & & & & & & & & & & & \\
\hline shr_15yr & 0.0844 & 1 & & & & & & & & & & & & & \\
\hline shr_wealthy & 0.0365 & -0.004 & 1 & & & & & & & & & & & & \\
\hline geo_access & -0.0258 & 0.015 & 0.0461 & 1 & & & & & & & & & & & \\
\hline road_flaw & 0.1746 & 0.2412 & -0.0389 & -0.0393 & 1 & & & & & & & & & & \\
\hline time_prov_n & 0.0512 & 0.1331 & -0.0636 & -0.1121 & 0.2402 & 1 & & & & & & & & & \\
\hline dist_sec_s 1 & 0.0113 & 0.1366 & -0.0001 & -0.0316 & 0.2168 & 0.1937 & 1 & & & & & & & & \\
\hline dist_bank & 0.1526 & 0.0761 & -0.0392 & -0.0421 & 0.1105 & 0.1406 & 0.2093 & 1 & & & & & & & \\
\hline shr_car & 0.0074 & -0.2126 & 0.047 & -0.0551 & -0.2527 & -0.1346 & 0.0014 & 0.0637 & 1 & & & & & & \\
\hline shr_electric & -0.1687 & -0.2804 & 0.0334 & -0.0562 & -0.4608 & -0.3032 & -0.4261 & -0.2529 & 0.1594 & 1 & & & & & \\
\hline shr_www & 0.0249 & -0.0746 & -0.0059 & -0.0263 & -0.0436 & -0.1143 & -0.0486 & 0.0362 & 0.1835 & 0.0731 & 1 & & & & \\
\hline Thailand & -0.1118 & -0.2732 & 0.0081 & -0.0342 & -0.3682 & -0.1491 & -0.0005 & 0.1014 & 0.6496 & 0.2511 & 0.183 & 1 & & & \\
\hline Vietnam & -0.1612 & 0.081 & 0.0074 & -0.0438 & 0.0567 & -0.0567 & -0.196 & -0.3041 & -0.5396 & 0.2106 & -0.1553 & -0.7655 & 1 & & \\
\hline Laos & 0.447 & 0.1462 & -0.0106 & 0.0523 & 0.265 & 0.275 & 0.1016 & 0.3389 & -0.0763 & -0.2856 & 0.0004 & -0.2481 & -0.2566 & 1 & \\
\hline Cambodia & 0.071 & 0.2434 & -0.021 & 0.1075 & 0.3623 & 0.1247 & 0.3066 & 0.0462 & -0.1429 & -0.664 & -0.0586 & -0.2096 & -0.2168 & -0.0702 & 1 \\
\hline
\end{tabular}

Table 5: Correlation matrix for the robustness check variables. 
(1)

$(2)$

(3)

(4)

(5)

(6)

Variables

hh_mphone hh_mphone hh_mphone hh_mphone hh_mphone hh_mphone

\begin{tabular}{|c|c|c|c|c|c|c|}
\hline hh & $\begin{array}{c}0.89^{* * *} \\
(0)\end{array}$ & $\begin{array}{c}0.88^{* * *} \\
(0)\end{array}$ & $\begin{array}{c}0.87^{* * *} \\
(0)\end{array}$ & $\begin{array}{c}0.87^{* * *} \\
(0)\end{array}$ & $\begin{array}{c}0.89^{* * *} \\
(0)\end{array}$ & $\begin{array}{c}0.86^{* * *} \\
(0)\end{array}$ \\
\hline \multirow[t]{2}{*}{ hh_commute } & $0.13^{* * *}$ & 0.054 & 0.0069 & 0.0016 & $0.13^{* * *}$ & $0.16^{* * *}$ \\
\hline & $(0.0032)$ & $(0.46)$ & $(0.93)$ & $(0.98)$ & $(0.0029)$ & $(0.00053)$ \\
\hline \multirow[t]{2}{*}{ hh_em_prov_rur } & $-0.71^{* *}$ & $-0.62^{* *}$ & $-0.60^{* *}$ & $-0.58^{* *}$ & $-0.68^{* *}$ & $-0.48^{*}$ \\
\hline & $(0.013)$ & $(0.017)$ & $(0.021)$ & $(0.027)$ & $(0.017)$ & $(0.064)$ \\
\hline \multirow[t]{2}{*}{ hh_em_prov_urb } & -0.033 & -0.078 & -0.030 & -0.037 & -0.044 & -0.010 \\
\hline & $(0.85)$ & $(0.67)$ & $(0.87)$ & $(0.83)$ & $(0.80)$ & $(0.95)$ \\
\hline \multirow[t]{2}{*}{ hh_em_coun_rur } & -0.91 & -0.90 & -0.87 & -0.96 & -0.93 & -0.90 \\
\hline & $(0.20)$ & $(0.22)$ & $(0.24)$ & $(0.20)$ & $(0.20)$ & $(0.18)$ \\
\hline \multirow[t]{2}{*}{ hh_em_coun_urb } & -0.17 & -0.12 & -0.10 & -0.100 & -0.16 & -0.14 \\
\hline & $(0.24)$ & $(0.42)$ & $(0.50)$ & $(0.52)$ & $(0.25)$ & $(0.30)$ \\
\hline \multirow[t]{2}{*}{ hh_em_city } & $0.51^{* * *}$ & $0.52^{* * *}$ & $0.52^{* * *}$ & $0.48^{* * *}$ & $0.51^{* * *}$ & $0.38^{* * *}$ \\
\hline & $(3.2 \mathrm{e}-06)$ & $(4.7 \mathrm{e}-06)$ & $(4.9 \mathrm{e}-06)$ & $(0.000011)$ & $(2.7 \mathrm{e}-06)$ & $(0.000078)$ \\
\hline \multirow[t]{2}{*}{ hh_em_abroad } & -0.50 & -0.49 & -0.50 & -0.49 & -0.46 & -0.48 \\
\hline & $(0.36)$ & $(0.37)$ & $(0.34)$ & $(0.36)$ & $(0.40)$ & $(0.35)$ \\
\hline \multirow[t]{2}{*}{ hh_gov_employ } & & 0.16 & 0.13 & 0.13 & & \\
\hline & & $(0.14)$ & $(0.21)$ & $(0.23)$ & & \\
\hline \multirow[t]{2}{*}{ hh_agri_work } & & & $0.064^{*}$ & $0.060^{*}$ & & \\
\hline & & & $(0.067)$ & $(0.084)$ & & \\
\hline \multirow[t]{2}{*}{ hh_foreigners } & & & & $4.11^{* * *}$ & & \\
\hline & & & & $(0.0013)$ & & \\
\hline \multirow[t]{2}{*}{ num_enterpr } & & & & & $0.68^{* * *}$ & \\
\hline & & & & & $(0.00012)$ & \\
\hline \multirow[t]{2}{*}{ vil_project } & & & & & & $12.4^{* * *}$ \\
\hline & & & & & & $(0.0011)$ \\
\hline Observations & 505 & 493 & 493 & 493 & 505 & 479 \\
\hline Adjusted R-squared & 0.975 & 0.974 & 0.975 & 0.975 & 0.975 & 0.975 \\
\hline
\end{tabular}

Robust p-values in parentheses:

$* * * \mathrm{p}<0.01,{ }^{* *} \mathrm{p}<0.05,{ }^{*} \mathrm{p}<0.1$

Table 6: Supplementary results. Reduced sample main regression results, leaving out villages without mobile phone use. 


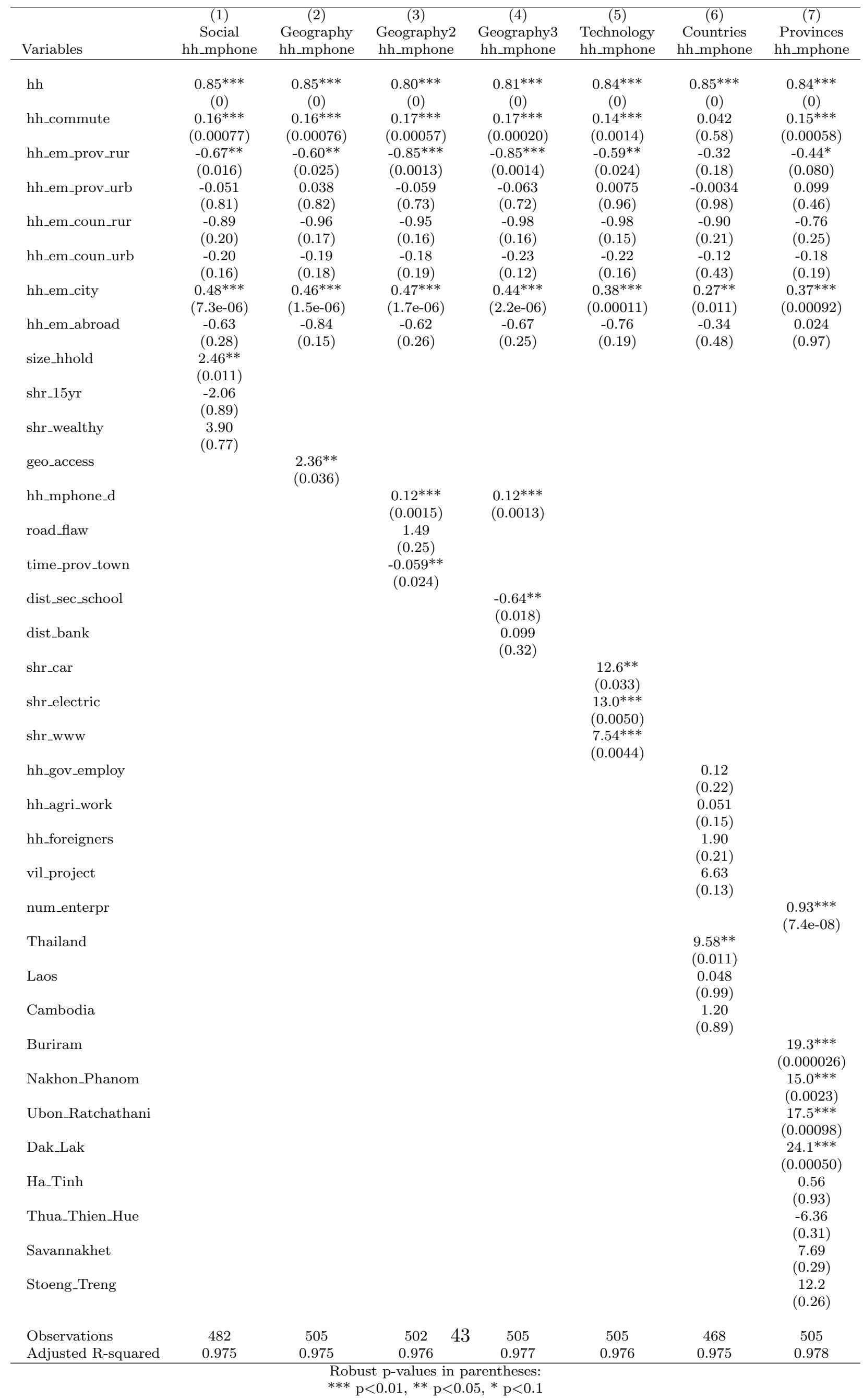

Table 7: Supplementary results. Reduced sample robustness check results. 
(1)

$(2)$

(3)

(4)

(5)

(6)

Variables $\quad$ hh_mphone hh_mphone hh_mphone hh_mphone hh_mphone hh_mphone

\begin{tabular}{|c|c|c|c|c|c|c|}
\hline hh & $\begin{array}{c}0.87^{* * *} \\
(0)\end{array}$ & $\begin{array}{c}0.86^{* * *} \\
(0)\end{array}$ & $\begin{array}{c}0.85^{* * *} \\
(0)\end{array}$ & $\begin{array}{c}0.85^{* * *} \\
(0)\end{array}$ & $\begin{array}{c}0.86^{\text {*** }} \\
(0)\end{array}$ & $\begin{array}{c}0.83^{* * *} \\
(0)\end{array}$ \\
\hline hh_commute & $0.15^{*}$ & 0.073 & 0.0074 & 0.0018 & $0.15^{*}$ & $0.19^{* *}$ \\
\hline hh_em_prov_rur & $\begin{array}{l}(0.054) \\
-0.66^{*} \\
(0.083)\end{array}$ & $\begin{array}{c}(0.49) \\
-0.57^{*} \\
(0.10)\end{array}$ & $\begin{array}{c}(0.95) \\
-0.53 \\
(0.12)\end{array}$ & $\begin{array}{c}(0.99) \\
-0.51 \\
(0.14)\end{array}$ & $\begin{array}{c}(0.055) \\
-0.62^{*} \\
(0.10)\end{array}$ & $\begin{array}{c}(0.022) \\
-0.40 \\
(0.27)\end{array}$ \\
\hline hh_em_prov_urb & $\begin{array}{c}-0.070 \\
(0.79)\end{array}$ & $\begin{array}{l}-0.12 \\
(0.68)\end{array}$ & $\begin{array}{r}-0.051 \\
(0.86)\end{array}$ & $\begin{array}{c}-0.059 \\
(0.83)\end{array}$ & $\begin{array}{l}-0.084 \\
(0.74)\end{array}$ & $\begin{array}{r}-0.042 \\
(0.87)\end{array}$ \\
\hline hh_em_coun_rur & $\begin{array}{l}-0.91 \\
(0.30)\end{array}$ & $\begin{array}{l}-0.89 \\
(0.30)\end{array}$ & $\begin{array}{l}-0.85 \\
(0.32)\end{array}$ & $\begin{array}{l}-0.95 \\
(0.28)\end{array}$ & $\begin{array}{l}-0.93 \\
(0.29)\end{array}$ & $\begin{array}{l}-0.93 \\
(0.28)\end{array}$ \\
\hline hh_em_coun_urb & $\begin{array}{l}-0.17 \\
(0.46)\end{array}$ & $\begin{array}{l}-0.12 \\
(0.61)\end{array}$ & $\begin{array}{l}-0.098 \\
(0.69)\end{array}$ & $\begin{array}{c}-0.094 \\
(0.70)\end{array}$ & $\begin{array}{l}-0.17 \\
(0.48)\end{array}$ & $\begin{array}{c}-0.14 \\
(0.53)\end{array}$ \\
\hline hh_em_city & $\begin{array}{c}0.63^{* * *} \\
(6.6 \mathrm{e}-06)\end{array}$ & $\begin{array}{c}0.64^{* * *} \\
(6.8 \mathrm{e}-06)\end{array}$ & $\begin{array}{c}0.63^{* * *} \\
(7.3 \mathrm{e}-06)\end{array}$ & $\begin{array}{c}0.59^{* * *} \\
(0.000015)\end{array}$ & $\begin{array}{c}0.63^{* * *} \\
(6.4 \mathrm{e}-06)\end{array}$ & $\begin{array}{c}0.46^{* * *} \\
(0.000087)\end{array}$ \\
\hline hh_em_abroad & $\begin{array}{l}-0.23 \\
(0.73)\end{array}$ & $\begin{array}{l}-0.21 \\
(0.76)\end{array}$ & $\begin{array}{l}-0.24 \\
(0.73)\end{array}$ & $\begin{array}{l}-0.22 \\
(0.75)\end{array}$ & $\begin{array}{l}-0.18 \\
(0.79)\end{array}$ & $\begin{array}{l}-0.24 \\
(0.74)\end{array}$ \\
\hline hh_gov_employ & & $\begin{array}{c}0.17 \\
(0.13)\end{array}$ & $\begin{array}{c}0.13 \\
(0.23)\end{array}$ & $\begin{array}{c}0.12 \\
(0.26)\end{array}$ & & \\
\hline hh_agri_work & & & $\begin{array}{c}0.087^{* *} \\
(0.039)\end{array}$ & $\begin{array}{c}0.083^{* *} \\
(0.049)\end{array}$ & & \\
\hline hh_foreigners & & & & $\begin{array}{l}4.43^{* * *} \\
(0.0064)\end{array}$ & & \\
\hline num_enterpr & & & & & $\begin{array}{c}0.81 \\
(0.60)\end{array}$ & \\
\hline vil_project & & & & & & $\begin{array}{c}15.8^{* * *} \\
(0.00043)\end{array}$ \\
\hline Observations & 508 & 496 & 496 & 496 & 508 & 481 \\
\hline Adj. $R^{2}$ & 0.961 & 0.961 & 0.961 & 0.961 & 0.962 & 0.963 \\
\hline
\end{tabular}

Robust p-values in parentheses:

$* * * \mathrm{p}<0.01,{ }^{*} * \mathrm{p}<0.05,{ }^{*} \mathrm{p}<0.1$

Table 8: Supplementary results. Bootstrapped main regression results with 1000 replications per regression. 


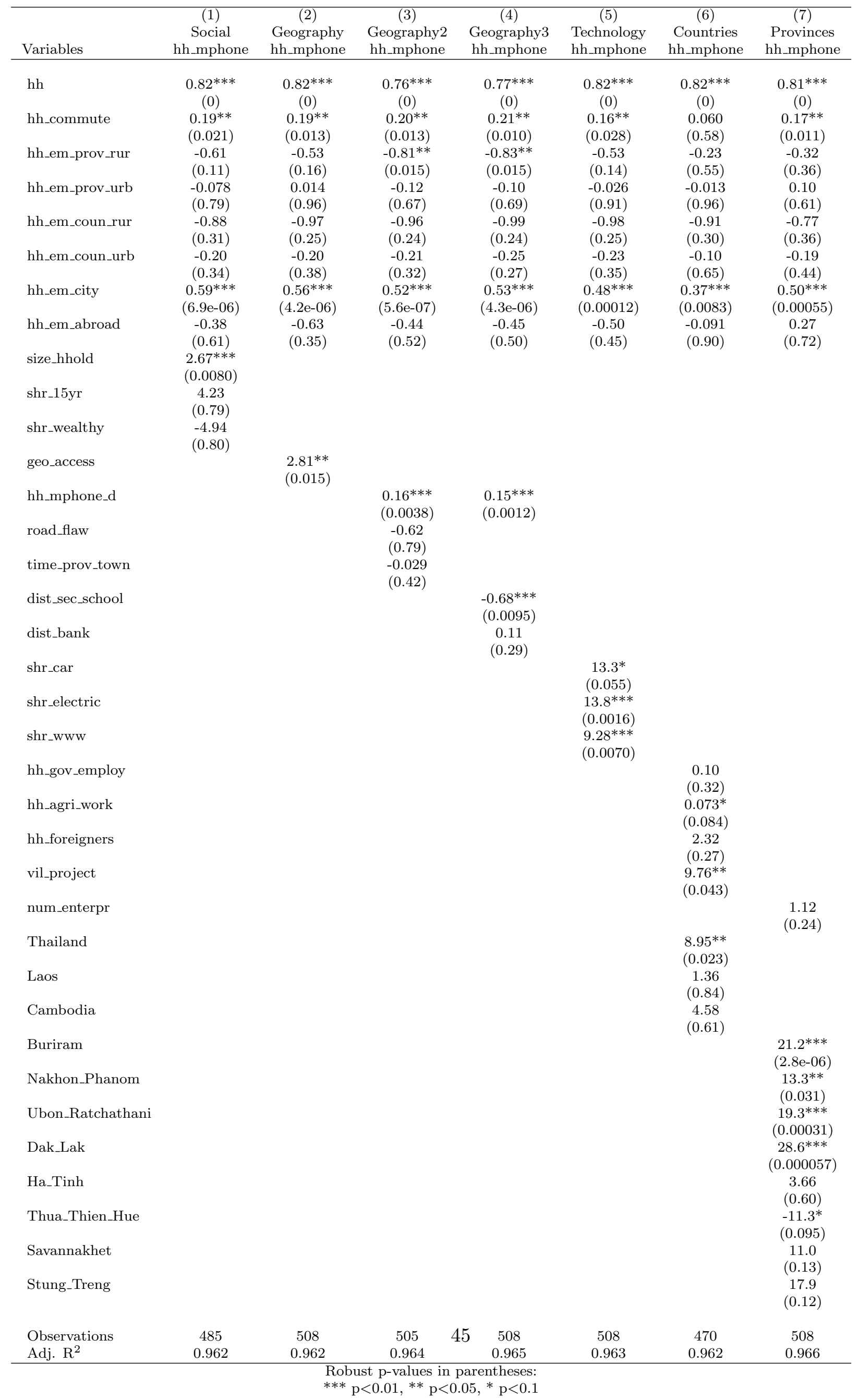

Table 9: Supplementary results. Bootstrapped robustness check results. 
(1)

$(2)$

(3)

(4)

(5)

(6)

Variables hh_mphone hh_mphone hh_mphone hh_mphone hh_mphone hh_mphone

\begin{tabular}{|c|c|c|c|c|c|c|}
\hline hh & $\begin{array}{c}0.87^{* * *} \\
(0)\end{array}$ & $\begin{array}{c}0.86^{* * *} \\
(0)\end{array}$ & $\begin{array}{c}0.85^{* * *} \\
(0)\end{array}$ & $\begin{array}{c}0.85^{* * *} \\
(0)\end{array}$ & $\begin{array}{c}0.86^{* * *} \\
(0)\end{array}$ & $\begin{array}{c}0.83^{* * *} \\
(0)\end{array}$ \\
\hline \multirow[t]{2}{*}{ hh_commute } & $0.15^{*}$ & 0.073 & 0.0074 & 0.0018 & $0.15^{*}$ & $0.19^{* *}$ \\
\hline & $(0.10)$ & $(0.62)$ & $(0.97)$ & $(0.99)$ & $(0.10)$ & $(0.039)$ \\
\hline \multirow[t]{2}{*}{ hh_em_prov_rur } & $-0.66^{*}$ & -0.57 & -0.53 & -0.51 & $-0.62^{*}$ & -0.40 \\
\hline & $(0.074)$ & $(0.11)$ & $(0.14)$ & $(0.16)$ & $(0.091)$ & $(0.27)$ \\
\hline \multirow[t]{2}{*}{ hh_em_prov_urb } & -0.070 & -0.12 & -0.051 & -0.059 & -0.084 & -0.042 \\
\hline & $(0.80)$ & $(0.68)$ & $(0.86)$ & $(0.83)$ & $(0.76)$ & $(0.86)$ \\
\hline \multirow[t]{2}{*}{ hh_em_coun_rur } & -0.91 & -0.89 & -0.85 & -0.95 & -0.93 & -0.93 \\
\hline & $(0.29)$ & $(0.32)$ & $(0.34)$ & $(0.32)$ & $(0.29)$ & $(0.24)$ \\
\hline \multirow[t]{2}{*}{ hh_em_coun_urb } & -0.17 & -0.12 & -0.098 & -0.094 & -0.17 & -0.14 \\
\hline & $(0.29)$ & $(0.48)$ & $(0.59)$ & $(0.62)$ & $(0.30)$ & $(0.35)$ \\
\hline \multirow[t]{2}{*}{ hh_em_city } & $0.63^{* * *}$ & $0.64^{* * *}$ & $0.63^{* * *}$ & $0.59^{* * *}$ & $0.63^{* * *}$ & $0.46^{* * *}$ \\
\hline & $(8.8 \mathrm{e}-06)$ & $(0.000015)$ & $(0.000020)$ & $(0.000036)$ & $(7.9 \mathrm{e}-06)$ & $(0.00011)$ \\
\hline \multirow[t]{2}{*}{ hh_em_abroad } & -0.23 & -0.21 & -0.24 & -0.22 & -0.18 & -0.24 \\
\hline & $(0.71)$ & $(0.73)$ & $(0.68)$ & $(0.70)$ & $(0.77)$ & $(0.67)$ \\
\hline \multirow[t]{2}{*}{ hh_gov_employ } & & 0.17 & 0.13 & 0.12 & & \\
\hline & & $(0.18)$ & $(0.31)$ & $(0.35)$ & & \\
\hline \multirow[t]{2}{*}{ hh_agri_work } & & & $0.087^{*}$ & $0.083^{*}$ & & \\
\hline & & & $(0.052)$ & $(0.066)$ & & \\
\hline \multirow[t]{2}{*}{ hh_foreigners } & & & & $4.43^{* * *}$ & & \\
\hline & & & & $(0.0085)$ & & \\
\hline \multirow[t]{2}{*}{ num_enterpr } & & & & & 0.81 & \\
\hline & & & & & $(0.71)$ & \\
\hline \multirow[t]{2}{*}{ vil_project } & & & & & & $15.8^{* * *}$ \\
\hline & & & & & & $(0.00053)$ \\
\hline Observations & 508 & 496 & 496 & 496 & 508 & 481 \\
\hline Adj. $R^{2}$ & 0.961 & 0.961 & 0.961 & 0.961 & 0.962 & 0.963 \\
\hline
\end{tabular}

Robust p-values in parentheses:

$* * * \mathrm{p}<0.01,{ }^{* *} \mathrm{p}<0.05,{ }^{*} \mathrm{p}<0.1$

Table 10: Supplementary results. Jackknifed main regression results. 


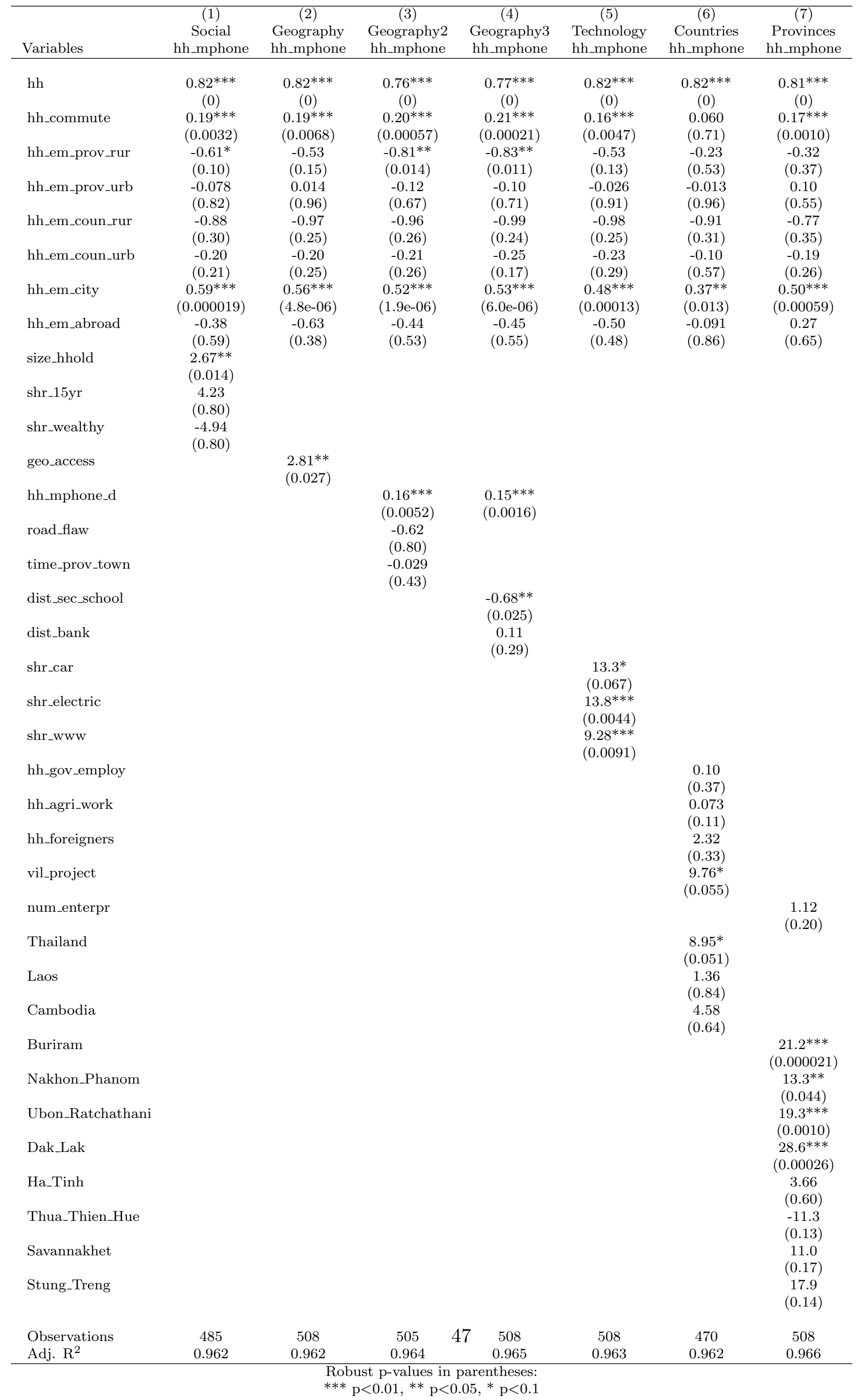

Table 11: Supplementary results. Jackknifed robustness check results. 